ANALISE TIA FENTAEILIDIALE ECONOKTCA IIA FFODUGHO DIE HOFTALIGAS DIO IIISTRIITO FEDIEFAL

\title{
CYFIO KUFIHAFiA
}

Ec on om is.st at

Orientador: Frof. [Ir. JOSE FERFETRIA IIE NOFONHA

Ilissertacăo apresentada à Escola Superior de Agricultura "Luiz de Queiróz", da Universidade de Săo Faulo, para obtencáo do titulo de Mestre en Agronomia, área de concentracăo: Economia Agrária.

\author{
F. I F A C I C A B A \\ Estado de Sä́ Faulo - Brasil \\ Junho - 1989
}


k96a

Kurihara, Cyro

Análise da rentabilidade econômica da produção de hortaliças do Distrito Federal. Piracicaba, 1989.

\section{$69 \mathrm{p}$.}

Diss. (Mestre) - ESALQ

Bibliografia.

1. Hortaliça - Aspecto econômico Distrito Federal. 2. Hortaliça - Produ. ção - Distrito Federal I. Escola Supê rior de Agricultura Luiz de Queiroz, Piracicaba:

$$
\text { CDD } 338.175
$$


ANALISE DA RENTABILIDADE ECONOKICA DA FRODUG'AO DE HORTALIGAS DO DISTRTTO FELEREAL

CYRO KURI.HARA

Aprovada em: 22.08 .89

Comissăo julgadora:

Frof. Dr. José Ferreira de Noronha ESALQ/USF

Prof. Dr. Fedro Valentim Marques ESALQ/USP

Dr. Guarany Carlos Gomes EMBRAF'A

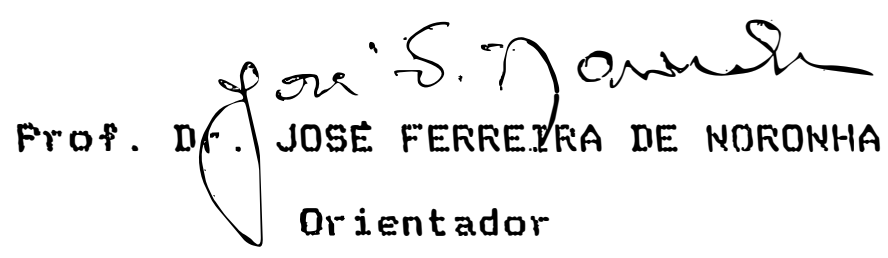


i. $i$

Aos meus ratis, Maria Helena, esposa ecompanheira e, aos meus filhos Andrea, Junior e lliogo Luis. DEnICo. 


\section{AGRAAIECIMENTOS}

A Empresa Brasileira de Fesquisa Agropecuá-ria - EMRGAPA e à Escola Superior de Agricultura "Luiz de Queirón" -.. ESALQ/USF, pela oportunidade de ampliar a for-.. macăo profissional.

Ao Frof. llr. José Ferreira de Noronha (ori-. entadori, pela presteaz é apoio.

Ao corpo docente do llepartamento de Economia e Sociologia Fural da ESALQ/USF, pelos ensinamentos recebidos, em especial an Frof. [ur. Fedro Valentim Marques e Frof. Hr. Evaristo Marabal Neves.

A Chetia do Centro Nacional de Fiesquisa de Hortalias CNFH/EMEFAFA, pelo apoio recebido durante a pesquisä.

$$
\begin{aligned}
& \text { Apresento tambem os meus agradecimentos aos } \\
& \text { do corpo tecnicos da Errififa, entre quas, }
\end{aligned}
$$
destaco:

[ir. Guarany Carlos Gomes (comorientador), pela incansável prestea e amizade demonstrado durante a execucro deste tratialio.

[lr. José lliniz de Araújo, [rr. Lucio Josí Uivaldi e lr. Levon Keganiantz, pelas valiosas criticase sugestöes apresentadas.

5r. Wagno Vasques de Aguiar pelas correcóes de texto deste trabalho. 


\section{BUMARIO}

Fígina

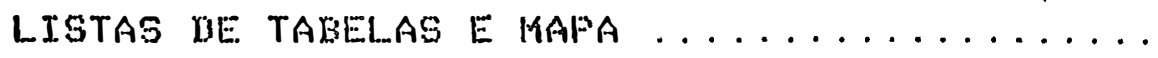

$v i$

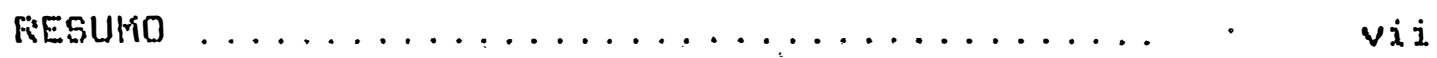

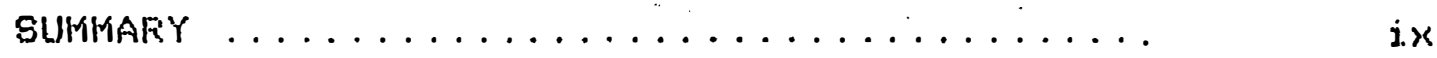

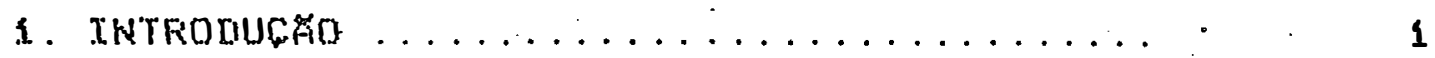

1.1. Ereve histórico da área rural do IfF.. 4

1.2. Caracteristicas da área rural do d.F.. b

1.3. A producato de houtalicas no IJF...... 9

1.2.3. Uso de inmumos e proticas ...

1.4. Froblema $e$ objetivos .......... 1s

1.4.1. Objetivos ............

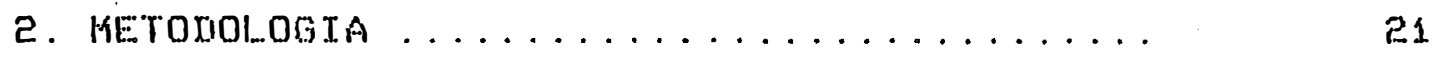

2.1. Base de dados ...............

2.2. Localiarăa das propriedadés .......

2.3. Informagós básicas .......... 2e

2.4. Avaliacăo da qualidade dos dados .... éc

2.5. Metodologia de análise .......... 25

2.ت.1. Fundamentos da análise de regressăo ............. es

2. S.e. Variáveis do modelo estatistico................

3. RESULTALOS E DTSCUSSAR :........... 32

3.1. Fesultados da análj.se descritiva .... 32

3.1.1. Estrutura econômica dos esta-

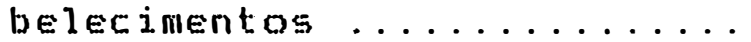


3.3. : Análise comparativa entre os

Fúgina dois grupos de produtores ...

3.1.2.1. Areas médias dos estabelecimentos .......

35

3.1.e.e. Tnvestimentos médias realizados........

3,5

3.1.2.3. Lespesas e receitas méd ias

37

3.1.3. Finaneiamentos bancários :...

39

3.e. Fesultados estatisticos .........

44

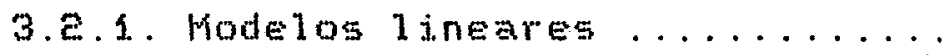

44

3.2.e. Modelos logaritmicos .......

55

4. Conchustes ................... S\&

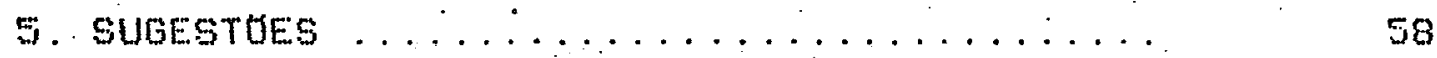

REFERENCIAS BTELIOGRAFICAS ..........

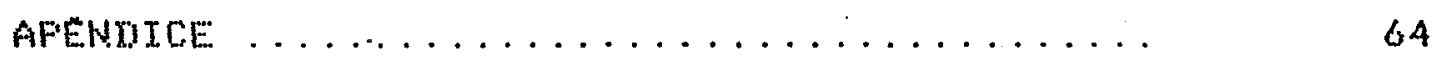

Aptendice $1 \ldots \ldots \ldots \ldots \ldots \ldots \ldots$

Apendice $2 \ldots \ldots \ldots \ldots \ldots \ldots$ 
vi .

\section{LISTA DE TABELAS}

Fógina

Tabela 1 -Fopulacóses urbana e rural do rif, 1936 .

Tabela e - Areas rurais administrada pela FZDF,

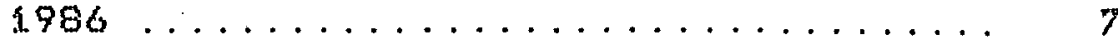

Tabela 3 - Fendimento médio de algumas hortaligas produardas no nF, $1985 \ldots \ldots \ldots \ldots$

Tabela of -.. Uso de insumos e pláticas mais adotados pejos horticultores do dif em 198e ....

Tabela 5 -. Volume comercial izado e producto das principais hortalicas do at, $1985 \ldots \ldots$

Tabela 6 - Número de producores de hortalizas entrevistados, segundo o nuteleo rural do of $e$ in $1906 \ldots \ldots \ldots \ldots \ldots \ldots$

Tabela 7 - Nivel de escolaridade dos produtores de hortalizas entrevistados em $1986 \ldots .$.

Tabela 0 - Media, desviomadrăo coeficiente de variarăo das principais variaveis ecom nomicas dos producores de hortalicas do Grupo 1 do IIF en $1986 \ldots \ldots \ldots$

Tabe 1 a 9 - Média, desviompadrấo coeficiente de

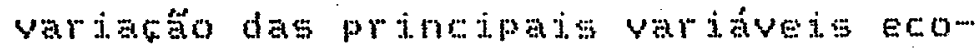
nomicas dos produtores de hortalifas do Grupo 2 do dif en $1986 \ldots \ldots \ldots \ldots$

Tabela 10 -valores escatisticos das regressbes lineres múteiplas dos dados da amostra dos produtores de hortalifas do $\mathrm{dF}$ em $\$ 986 \ldots \ldots \ldots \ldots \ldots$

\section{LISTA DE MAPA}

MAFA 1 - Wúcleos rurais do SF e número de produtores participantes, $\$ 906 \ldots \ldots \ldots$ 
$v i i$

\section{ANALISE DA RENTABTLIDADE ECONOMTCA DA FRODUGAO DEE HORTALIGAS DO DITSTFTTO FERERAL.}

Autor: CYFO KUFIHAFA

Drientador: Prof. Dr. JOSE FEFRETFA DIE NORONHA

FEESUKO

Este crabalho tem por objetivo a análiseda rentabilidade economica da produsa de hortalicas no Distrito Federal (DF), buscando determinar os fatores que aretam o nivel de renda dos producores.

As informaçós utilizadass para a análise, Poram obtidas junto a 76 produtores de hortalicas amostrados en 14 núcleos rurajs do nF, em 1906, mediante apli... catáto de questionários. Esse levantamento foi realizado pelo Centro Nacional de Fesquisa de Hortalicas - CNFH da Empresa Brasileira de Pesquisa Agropecurina - EMBfifa, com o objetivo de atender às exigencias de um frojeto referente aos "Impatos sóciomeconomicos da Fesquisa de Hortalicas da EMBFAPA".

Para atender o objetivo desta pesquisa, foi feita, inicialmente, uma análise descritiva das principais caracteristicas dos produtores de hortalicas do DF e, em seguida, uma análise de rentabilidade, utilizando como 
Vi.i.

instrumento a andisge de regressăo chorma linear e loga-ritrical, ajustando-se os dados pelo metodo dos Minimos Quadrados Drdinários.

Os resultados estatisticos mostraram que os dados da amostra se ajustaram melhor na forma linear, do que na forma logarituica.

A análise de regressä́, mostrou que a renda bruta dos produtores esta diretamente relacionada com a área plantada, gastos com defensivos, investimentos em máquinas equipamentos e gastos com măo-de-obra. A renda bruta está negativamente relacionada com a distancia da proprizdade.

As demais variáveis consideradas, investimentos em bentedtorias, gastos com adubos e nivel de escolaridade, năo se mostraram estatisticamente significativas na anólise da renda bruta.

A renda liquida dos produtores relacionouwe positivaments com a área plantada com os gastos com defensivos. 0s investimentos em benteitorias, gastos com adubos e distancia da propiriedade afetaran a renda liquida de modo negativo.

Jnvestimentos em máquinas e equipamentos, gasto: com mäomde-obra nivel de escolaridade, năo se mostraran estatisticamente significativas na análise de renda liquida dos produtores de hortalioas do IF. 
ix.

FROFITABILITY ANALYSTS OF VEGETABLE FRODUCTION IN THE FEDERAL DTSTRICT

Author: CYFO KUFTHAFA

AdvisEr: FrOH. Dr. JOSE FERFETFA DE NORONHA

\section{SUHHAFY}

This study aims to analize the profitability of vegetable production in the Federal District to identify the factors that contribute to the income level of the producers.

Data was obtaned from 78 vegetable far mers in 14 rumal commutejes of the Federal pistrict in. 1986, through a questionnaire. The survey was underlaken by the Nacional Center for Horticultural Fesearch - CNFH of the Erazilian Agricultural Fesearch Corporation EKBFAFA as a part of a project studying the socioeconomic i.mpact of vegetable reserith.

A descriptive analysis of the principal caracteristics of farmers included in the survey was done. Then a regression analysis (linear and logarithmic) using ordinary least squares method was undertaken.

The results show a better fit for linear functions as compared fo the logaribluic functions. 
The regression analysis showed that grosis income was directly related to cultivated area, pesticide expenditures, investments in machinery and equipment and labor expenditures. Gross income is negatively related to the distance from the farms to terminal markets.

Investments in machines and farm equipment, labor expenditure and education. level were not statistically significant as dependent variable in explaining gross income.

The producer. net income is positively related to area under crop and pesticide expenditure. The building investments; fertilizer expendjtures and distance from the farms to the markets affect, net income negatin. Vely.

other variables considered, such as machinery and gqupment, labor expenditures and education level, did not show significant results in the net income analysis of the Federal pistrict vegetable farmers: 


\section{INTRONUGín}

o Distrito Federal (DF) está localizado na regiăo Centro-oeste, na parte mais elevada do flanalto

- Central com a altitude máxima de 1158 m (LONGO, 1985).

Em 1986, sua populac ăo era de 1.61 .4 .929 ham bitantes, sendo que apenas 47.285 pessoas constituiam a populacko rural, representando $2,93 \%$, enquanto $97,07 \%$ estavan distribuidos em dez (10) centros urbanos (Tabela 1).

A área do $\mathrm{DF}$ é de $5.81 \mathrm{~A} \mathrm{kme}$, dos quade 474.899 ha $(84,7 \%)$ săo destinados \pm área rural. Esta gituado sob solos de cerrado cujas.caracteristicas săo: baixa fertilidade, acidez elevada dos solos e susceptibilidade à erosấo devido ao clima (intensidade de distribuicto da pluviometria), permeabilidade do solo, extensăo do declive acentuado etc. En face da peculiaridade de seus solos, elevadas quantidadés de calcario, matéria organica, fóstoro etc: sấo exigidas para o cultivo de hortalicas no cerrado (COMISSAOO DE FLANEJAKENTO AGRTCOLA DO IISTRITO FEVERAL - CEFA/DF, 19833.

o clima é caracterizado por uma mescla dos tipos "tropical de savana" e "temperado chuvoso de inverno seco" e apresenta duas estaföes bem definidas. Segundo 
Tabela 1 Fopulacóses urbana e rural do DF, 1986.

\begin{tabular}{|c|c|c|c|}
\hline \multicolumn{2}{|c|}{ Iocalidades } & populacăo & $(\%)$ \\
\hline \multirow[t]{5}{*}{ ZONA } & URBANA & 1.567 .644 & 97.07 \\
\hline & Flano Piloto & 351.873 & 20,45 \\
\hline & Cruzeiro & 60.1127 & 3,84 \\
\hline & Guará & 127.946 & 8,16 \\
\hline & Núcleo Bandeirante & $\cos 01.4$ & 1,40 \\
\hline & Gama & $170.2 A A$ & $10 ; 86$ \\
\hline & Taguatinga & 241.001 & 15,37 \\
\hline & Ceil Andia & 439.238 & 28,02 \\
\hline & Brazlând $i a$ & 25.285 & 1.61 \\
\hline & Sobradinho & $77.9 A$ & 4,95 \\
\hline & Flanaltina & 52.372 & 3,34 \\
\hline ZONA & FUFAL. & 47.285 & 2,93 \\
\hline IIIST & ITD FEIIEFAL & 1.614 .929 & 100,00 \\
\hline
\end{tabular}

Fonte: Anuário Estatstico do Iistrito Federal (1986).

\section{(1.)}

RETS, de maio a setembro ocorre uma estacáo seca e fria, registrando, em certos periodos, precipitacós inferiores a 30 mom de chuva. As temperaturas medias săo inferiores a

(1) REIS, N.U.B. (EMBRAFA. Centro Nacional de Fesquisas de Hortalicas). Brasilia, rof Comunjeacáo pessoal. (1988). 
$30^{\circ} \mathrm{C}$ durante o dia abaixo de $15^{\circ} \mathrm{C}$ no periodo noturno, com umidade relativa do ar varjando de 40 a $65 \%$, regism trando, em certos periodos do dia, menos de $15 \%$.

A estación úmida equente que cobre os demais meses do ano é caracterizada pela ocorrencia média de $80 \%$ da precipitacáo anual de 1.500 moproximadamente.

As temperaturas médias sás superiores a $30^{\circ} \mathrm{C}$ durante o dia e acima de $17^{\circ} \mathrm{C}$ no periodo noturno, com umidade relativa do ar variando de 70 a $80 \%$

A distribuicăo de chuvas é um forte condi-. cionante na producto agricola da regiáto, porsm, a preci... pitacăo anual ś suficiente para a maioria dos cultivos. Uma das praticas utilizadas pelosagricultores que năo

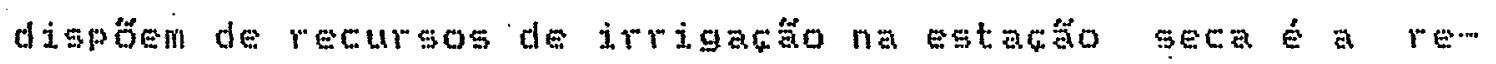
ducto do uso de insumos, buscando uma prática de producăo, na qual consiga combinar risco climatico com o de investimento. E possivel que essa seja uma das causas da baixa receptividade de manejo mais avancados, como a adocáo de niveis de adubacto compativeis com as condicoses de baixa fertilidade do solo, bem como o retardamento da expansăo da área cultivada no cerrado (CEFA/Ml, 1983).

Essa prática é também explicada por FAsTofe (1976), que caracteriza o setor agricola como uma das atividades mais complexas, ein razáo da incertera 
sobre jumeros fenomenos climáticose biolódcos, além da grande quantidade de variaveis que afetam a lucratividade do produtor. Isso faz com que o processo de decisäo do produtor seja cercado de inseguranga, dificuitando o processo de adocão de tecnologias modernas e comprometendo. o resultado económico no estabelecimento.

\section{1. Breve Histórico da Area Rural do Ilistrito Federal}

Quando da definicăo dos limites da área do novo Iistrito Federal e da aprovacto do plano diretor para a constructio de Brasilia, em 1956 , a primeira medida tomada pelo poder público foi o reordenamento da estrutura de posio da propriedade rural, das áreas desapropriadas dos municipios goianos de Formosa, Flanaltina e Luziânia.

Com o intuito de preservar as terras da especulatáto jmobiliaria, o Governo optou pela manutencăo, nas máog do poder público, das áreas desapropriadas por interesse social, introduzindo o sistema de arrendamento a chefes de familia com experiencia agricola comprovada (FEEAYLE, 1.971).

Segundo BFUNO $(1976)$, esse sistema assume caractersticas difersutes das usualmente contecidas, em razấo de que o proprietário das terras o o proprio Governo, resultando na transformacấo de uma economia agrária tradicional (latifúndio), para uma ecoromia sob certos aspectos quase socializantes, onde a producáo agricola 
representasso a base do desenvolvimento do of.

o sistema de arrendamento no rF tem sido apertejozado por leis e decretos ao longo dos anos e aprem senta as seguintes caracteristicas:

1) Prago de 15 anos (renováveis) transferivel aos herdeiros;

-) en caso de rescişa contratual, há a indenizacăo pelo Governo das benfeitorias realizadas pelo arrendatário;

3) taxa anual de arrendamento é de $5 \%$ do Maior Valor de Feferencia (MUA) da regiăo, por hectare;

4) após 5 anos de contrato, o arrendatio pode vender o direjto terejos, com anutanej do Governo;

5) o Soverno pode direcionar a exploracto agricola, vjsando aos altos interesses da comunidade, vinculando o contrato de arrendamento a um plano de litilizacto raciona? (CEPA/DF, 1983$)$. 


\subsection{Caracteristicas da Area Rural do Distrito Federal}

Náo obstante a extensăo de 474.899 ha destinada à área rural, somente $226.390,7$ ha $(47,7 \%)$ encontravam-se ocupados Em 198 A (ANUAFIO ESTATISTICO DO UF, 1986). Deste montante, uma parte está sendo administrada pela Fundacáo Zoobotanica do Distrito Federal (Fzof), compreendendo, em 1986, uma área de 1.44.618,e ha, distribuídos em núcleos rurais, colonias agricolas, agroyilas, projetos éreas especiais (Tabela 2 ).

os nucleos rurais e as colonias agricolas diferem basicamente pelo tamanho dos lotes funca so social. Enquanto os primeiros apresentam Iotes relativamente matores eproducso dirigida comercializacto para abastecimento do mercado, as diltimas sêm tamanho reduzido a producăo cumpre a functo social de subsistência, sendo os seus produtores caracterizados como de baixa renda.

o nucleo rural e constituido de grandes áreas subdivididas em lotes que variam de 4 a 300 ha, dependendo da sua destinaçón. As áreas mais próximas à zona urbana compóem-se de lotes menores, destinados a producăo incensiva de hortalitas. Ds iotes de 20 a 50 ha foram reservados à producto de outros produtos arimentares básicos e os lotes majores, de 50 a 300 ha, para pecuaria e outras exploracöes agricolas. 
Tabela 2 - Areas rurais administradas pela Fzof - 1986

\begin{tabular}{|c|c|c|c|}
\hline Areas rurajs & Quant idade: & $\begin{array}{l}\text { No. de } \\
\text { lotes }\end{array}$ & Area (ha) \\
\hline Núcleos rurais & 16 & 1. . 257 & 69.339 .0 \\
\hline Colonias agricolas & 12 & 646 & 10.708 .9 \\
\hline Agrovilas & .04 & 103 & 29,2 \\
\hline Frojetos especiais & $0 \%$ & 703 & $1.7,062,6$ \\
\hline Areas especiais & ees & ees & $47.478,5$ \\
\hline $\operatorname{Tota} 1$ & 260 & 2.230 & 144.618 .2 \\
\hline
\end{tabular}

Esses núcleos rurais sato dotados de infraestrutura mínima necessária para apoio, como: escolas, postos de assistencia técnica e saude, revenda de insumos agropecusirios e comércio yarejista de secos e molhados (administrado pelo Goyorno do nistrito Federal - GIF) E centros comunitarios. Alguns já dispótem de mercados de produtores; como estrutura de comercializacto de seus produtos (EMPRESA DE ASSTSTENCTA TECNTCA E EXTENSAO RUFAL - EMATER/DF, 1988).

As colônins agricolas não dispótem da mesma infra-estrutura existente nos nucleos rurais, limitando-se em alguns casos a contar com escolas, postos de sacide e Centros comunitátios (CEFA/RIF, 1983). 
8.

As agrovjlas sto nucleos de residencjas de trabalhadores rurais, dotados de escolas, centros comuntárjos, postos de saude, prafas de esportes, casas de farinha ou outro tipo de indústria caseira.

As áreas especiais ou isoladas sơo destinadas a projetos agropecuários de grande porte (EMATER/IF, 1988).

Há, ainda, sob administracăo do Instituto Nacional de Colonizacto feforma Agrária (INCFA), o from jeto Integrado de Colonizacto Alexandre Gusmato, abrangendo uma área de 23.000 ha, tendo.os lotes uma área média de 5 ha. Este projeto foi implantado com finaljdade de promover, no mo, a producto da hortifrutigranjejros e confew rir o titulo definitivo aos proprietarios para facilitar o acesso ao crédito e financiamento bancério (CEFA/LF, $1983)$

A partir de 1977 , o Banco Central autorizou a concessăo de financiamento rural aos arrendatarios, sob a garantia dos direitos do contrato de arrendamento, pojs. ate entăo, os arrendatános tinham dificuldade na obtencắo dos financjamentos compativeis com os gastos de custejo e investimento para a producto (BFuNo, 1976).

Alem das ámeas arrendadas pelo Governo, as areas rurais também sâo ocupadas por reservas naturais, parques e áreas de dominio de órgấos publicos cinclusive das Forcas Armadas), abrangendo cerca de $130.000 \mathrm{ha}$, sendo 
que algumas dessas áreas encontram-se en processo de regularizacto juridica (EMATEF/OF, 1988 ).

Apesar dessa estrutura de ocupacáo das ter ras, existem, ainda, fireas năo desapropriadas e que perma necem nas mäos de particulares, ocorrendo grande especulaGáto jobiliária, apesar da preocupacăo do governo, gerando elevado numero de pequenas chácaras. geralmente improdutivas utilizadas para lazer (BRUNo, 1976).

\subsection{A Froduçáno de hortalicas no nistrito Federal}

A agricultura no ru temse caracterizado pela produsto de alimentos voltada para o abastecimento do mercado interno, reduzindo, ao $10 n g o$ do tempo, a dependencia de abastecimento de outros centros produtores tradici... onais. Essa preocupaço deveu-se, principalmente, a dois fatores:

1) distancia de Brastilia dos centros produtores, fator que onerava sobremaneira o custo dos alimentos, representando uma pesada carga no oramento da populastó

e) necossidade da redurăo de dependencia da nova capital da Republica em relatáo a outras áreas.

niante disso, a auto-suficikncia de abas tecimento agricola passou a ser un desalio ao Governo, principalmente levando em consideracto a falta de tecnologia para a regiân do cerrado. Nessa perspectiva, o de- 
senvolvimento das atividades de pesquisa, da assistencia técnica e da acto pioneira dos produtores vindos de outras regiós do Brasil, ou mesmo do exterior, foi decisivo para alcancar os objetivos de abastecimento para a populacäo do DF (EMATER/UF, 1988 ).

A producăo de hortalicas 2 uma das atividades agricolas que mais se destacaram ra regiăo. Ds rendimentos médios, em 1986, alcancaram niveis superiores às da média nacional, destacando-se o chuchu, a batata, a batata-doce outros (Tabela 3 ).

A produca de hortalicas no uf apresenta um padräo regularmente repetido em duas épocas do ano:

1) nos meses úmidos equentes, o desenvolvimento das culburas t bastante dificultado por excesso de chuvas, causando elevacáo da umidade relativa do $a r$, quando associado às altas temperaturas, favorece a incidéncia de doencas e pragas, principalmente nas culturas de tomate, batata e outras;

e) nos meses secos e frios, as culturas se desenvolvem com mator facilidade, devido à baxe incidencia de pragas e doencas, sendo, no entanto, indispensaved o uso de 1. sistema de irrigacto na producăo (RETS).

De modo geral, na primeira época os rendimentos sáo mas baixos, diminuindo sobremaneira a oferta 
Tabela 3 - Fendimento médio de algumas hortalicas produzidas no of, 1986.

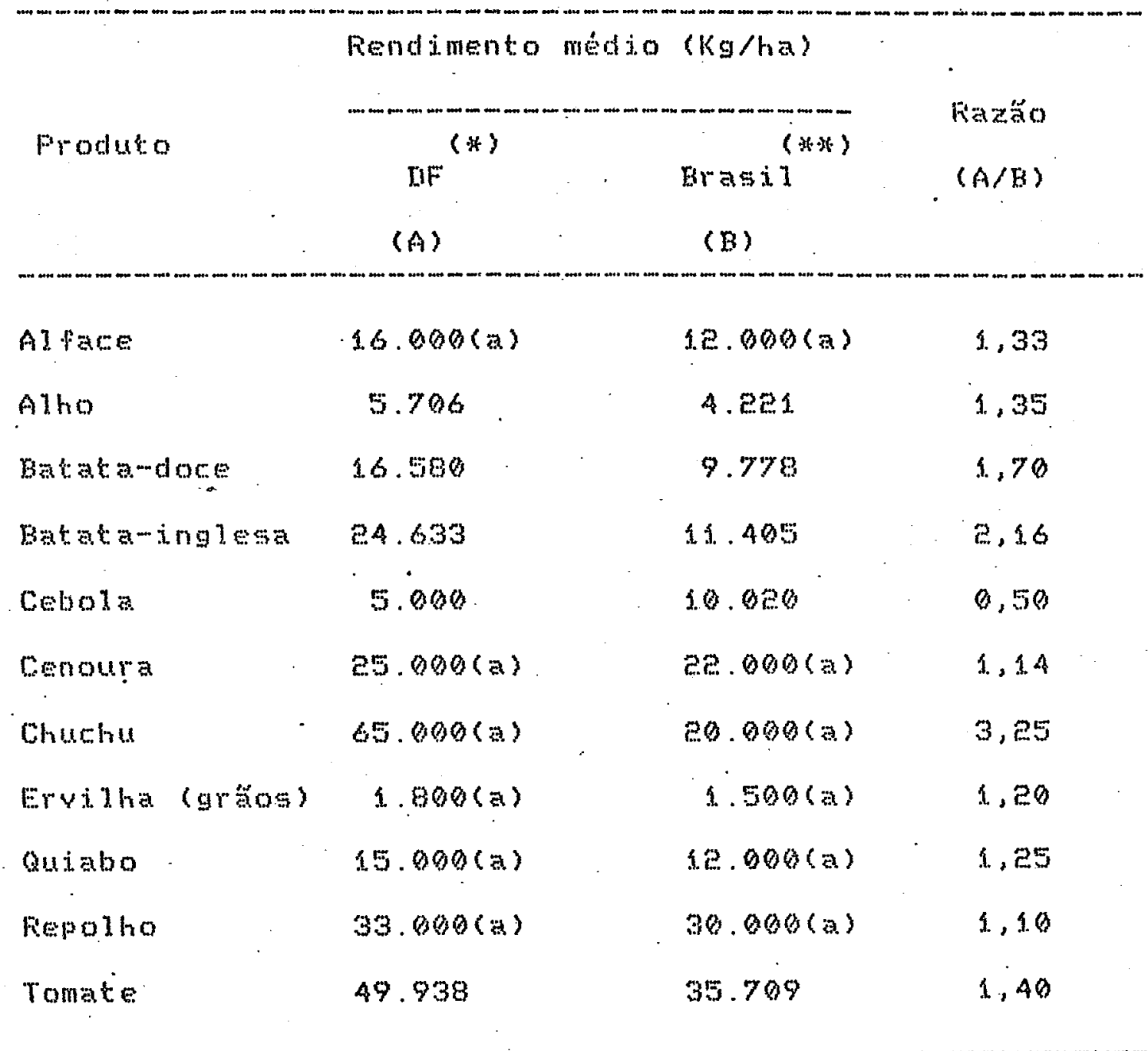

Fontes: (*) Anuário Estatistico do If (1986).

(**) Anuario Estatistico do Brasil (1986).

(a) OLIVEIFA et alii (1998). 
no mercado e, por conseguinte, a necessjade de importacäo do produto de outros Estados, prinedpamente de beterraba, cebola, alho e outros, acarretando en precos mais altos. No segundo periodo, os precos säo majs baixos, pois as quantidades oferecidas sato relativamente maiores; em con-gequência, os precos também apresentam um padrấo regularmente repetido e de sentido contrário ao das quantidades (CASTOR \& STLUA, 1986 ).

IIE acordo com UENO \&. AMAFO (1980), as hortalicas aprosentam caracteristicas diferentes em relaba a outros produtos agricolas, principalmente nos aspectos de producta (ciclo curto), nita perecibilidade do produto - das variacóses estacionais nas quantidades ofertadas, cujos efeitos refletem nos precos.

Dutra caracteristica marcante na producáo de hortalicas é o carater intengivo, principalmente no que se refere a utilizacto da sres, tratos culturais, môde-obra e insumos (adubos, defensivos, sementes etc.), notando-me a crescente utilizacto de equipamentos modernos na krea producora.

E bastante elevada a proporaz̃o de produtores que utilian sementes selecionadas, sistemas de irrigacto mecanizados, adubacto ecalogem etco (Tabela 4). 
(e)

No estudo de Gores et alij, os niveis de rendimento medio alcancados pelos produtores de hortalicas do of sato atribuidos, em parte, ao uso em njvel elevado de insumos ede praticas modernas de producáo, aliados aos esforcos conjugados das diversas instifuigós (pesquila, extensăo rural e bantaria) que atuan no ro.

\subsubsection{Uso de insumos e praticas}

(e)

Segundo pesquisa de comes et ali. baseado nos dados da amostra dos produtores de hortalicas do lin em 1982, a grande maria (mais de 80\%) dos produtores de hortalicas udilizam insumos modernose adotam práticas agricolas avancadas. A utilizacóo de insumos e práticas modernas, tem cono objetivo garantir altos rendimentos e produtos de major preso na cotacio do mercado.

As praticas menos utiliaras pelos produtores do fif sâo adubatâno verde $(17,0 \%)$ e controle biologico de pragas doencas $(10,0 \%)$, além de outras recomendados pelas instituigos de pesquisas e extensăo rural que sấo utilizadas por reduzido numero de

(2) GOKES, G.C.; CASTOF, O.S.; QUTWREFE JUNTOR, R. (timpresa Brasilejra de Fesquisa Agropecuáma, Bra si.ja, of . Estudo sobre producto de hortalifas no aF. (Em elaboracaro). 
produtores, a saber:

a) tratamento de sementes;

b) andise de solos antes da adubactó

c) utilizacto de adubos te defensivos em niveis recomendados pelos técnicos da extensto rural etc.

A olericultura requer o uso intensivo de capital (sistem de irrigacto, vefoulo, insumos e outros), mas é uma atividade que possibilita obtencato de altos irendimentos fisicose major frenda Liquida por unidade de Tabela 4 - Uso de Insumos priticas mais adotados pelos horticulicom do nir em $198 \mathrm{~g}$.

Insumos / praticas

Sementes e mudas selecionadas

bistema de irrigacóo (mecanizada)

Controle de ervas (eapina)

Controle de ervas (herbicidas?

Adubaçơo orgânic a

Adubactio $N F K$

Calagem

Controle de pragas (inseticidas)

Controle de doencas

\section{$(\%)$}

100,0

97.0

97,0

63,0

93,0

93,0

87,0

87,0

80.0

Fonte: Golves et a lid. 
área cultivada, possibilitando um refinamento de fecnologia, em grau majs elevado que nas demais exploracóses agricolas. Fossibilita, ainda, a geragăo de grande numero de empregos (uso intensivo de mäomemobra desde a semeadura até a comercjalizafâo) mantém. o solo ocupado ao longo do ano.

A producto regional de hortalicas é colocada, principalmente, na central de Abagtecimento do bistrito Federal $5 / A$ (CEASA/DF), estimandowse que por ali passe aproximadamente Bot da producto local. o restante é vendido diretamente pelos produtores no comercio varejista, quitandas, supermercados feiras-livres. Alguns produtos tém sido deslocados para estados vizinhos (CEFA/UF, 1.983). 


\subsection{Froblema objetivos}

A producăo de hortalicas no bistrito Federal tem aumentado significativamente nos útimos anos, abastecendo quase a totalidade das necessidades do mercado interno (Tabela 5 ). Tem condicóses de, em futuro próximo, atender o aumento da demanda das regiôses deficitarias, bem cono aumentar a oferta para o setor industrial (principalmente ervilha, tomate rasteiro e milhomdoce) e para o mercado externo ras formas "in natura" e "processadas" (como pimentäo, inhame, aspargos, ervilhas etc), sem comprometer o abastecimento do DF.

- aumento da producáa de hortaligas no uf poderá ser conseguido por duas maneiras:

a) expansaro da fronteira agricola, utilizando as tecnologias disponiveis para o manejo dos solos de cerrado;

b) aumento do rendimento médio, através do uso de técnicas majs eficientes.

Fara a expansấo da fronteira agricola, o IF possuia, ainda em 1984, grande área disponivel, pojs dos 2e6.390,7 ha que compöem a area rural $(47,7 \%$ do total da firea destinada), somente $92.751,3$ ha $(4 f, 0 \%)$ estavam ocupados ou em vias de exploracăo e 8e.684,3 ha $(36,5 \%)$ de áreas aproveitáveis, porém nắo exploradas (ANUAfio ESTATISTTCO DO OISTRITO FEDERAL, 1986). 
Tabela 5 - Volume comercializado e producáo das principais hortalinas no DF em 1.986.

(En tonelata)

\begin{tabular}{|c|c|c|c|c|}
\hline Froduto & $\begin{array}{l}\text { mercializado } \\
\text { (A) }\end{array}$ & $\begin{array}{l}\text { Froducão } \\
\text { (B) }\end{array}$ & $\begin{array}{l}B / A \\
(x)\end{array}$ & \\
\hline Alface & 1. 960,0 & 1. $1.47,0$ & 98,5 & \\
\hline Batata-inglesa & $18.661,0$ & $11.613,0$ (a) & 62,0 & \\
\hline aeterraba & 2.12e, & 2.006 .5 & 94,5 & \\
\hline Cenoura & 6.763 .2 & $5.3 .879,0(3)$ & 20,2 & \\
\hline chuehu & $3.746,8$ & 3.250, & 86,8 & ‘ \\
\hline Pepino & 1. $.53 \%, 6$ & 3. .025 .5 & 66,7 & \\
\hline Finent ẫo & 1.836 .7 & $1.09 \mathrm{e}, 4$ & 99,5 & \\
\hline Fepollo & 4.795 .9 & $4.180,1$ & 87,2 & \\
\hline Tomate & $15.636,0$ & $9.772,0$ & 62.5 & \\
\hline
\end{tabular}

Fontes: Acompanhamento mensal do produto CFASA/CIF, (9.98S).

(a) Informativo da Froductio Agricola -.. EMATEF/RF, $(1986)$

Segundo RICHTEE \& KONSEN (1979), a extenSta da áre cultivada e rendimentos sto elementos fundamentais para uma andise sobre aumento da producáo ou melhoria de abastecimonto de produtom agricolas.

os aumentos de rendimentos indicam menor utilizacão de recursos para a productio de uma unidade de produto. En certas condicooses, os acrescimos de rendimento 
1.8 .

agricola traduzen-me em aumentos de producăo a precos relativamente mais baratos ou, entäo, contribuem para a estabilizacto dos precos. Fortanto, à medida em que os precos dos produtos pressionam o custo de vida, o aumento do rendimento medio contribue positivamente para o combate a inflacío. Como os consumidores de baixo poder a quisitivo gastam grande parte do seu ormento com alimentos, eles só os matores beneficiarios do processo. Assim, o aumento do rendimento contribui para aliviar as tensobs existentes nas cidades e melhorar a dieta almentar de suas popula-

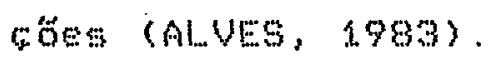

De acordo com AUTLA et alii (1985), grande número de agricultores provententes de familias de sitiantes e colonos dos Estados da regiâo Sul, estabeleceramse nas novas areas do cerrado e de fronteira como novos empresários, fazendo sucesso com uma agricultura comercial E de alto nivel tecnológico.

Os produtomes do nF näo utilizam muito as facilidades do credito bancario e tampouco auferem rendas que năo sejam do trabatho na propriedade (Lovoo, 1985), podendowe inferir que a atividade dispöe de condibes para crescimento autosustentado, com base nas rendas geradas pelo setor.

Os produtores do dIF apresentam caracteristicas diferentes em relacăo maioria dos produtores de outras partes do Brasit, possuindo muitos anos de escola 
ridade e procedentes de regiôsen majs desenvolvidas do Fais ou do Japa (LONGO, 1985).

No estudo de RICHTER \& KONSEN (1979), na busca de explicacöes para diferencas no rendimento dos agricultores, nem sempre se encontra a correspondencia es perada entre a adotân de praticas os aumentos de produtividade, ou entre a adotato o aumento de renda. Fortanto, naso parece correto busear uma resposta para o rendi... mento somente nos insumos modernos, de natureza quimica e biológa, sem levar em consideracto a capacidade adminis.... trativa do produtor, educaço formal, informacto técnicia, manejo da producho etc., pots essas evidencias podem aretar significativanente os resultados em termos de safra ou de renda.

A importancia da qualificacáo do produtor também foi estudada por SCHULTz (1965), segundo o qual, as diferenas existentes na producáo agicola entre os paises explicada, fundamentalmente, pelas diferencas na capacitacto dos produtores na condusto da atividade agricola. Existe um relacaso positiva entre o nivel das habilidades e do conkecimento dos agricultores e o nivel de rendimento.

Fortanto, pressupöenge neste estudo que o nivel de habilidades, conhecimento capacitacăo dos produtores están associados com o seu nivel de escolaridade. 
Baseado nessas caracteristicas, propöe-se o estudo da analise de rentabilidade econonica da producto de hortalifas no por, associando as caracteristicas dos produtores com os fatores de producto tradicionais, niveis de utilizacko dos jnsumos e tecnologias modernas.

\subsubsection{Objetivas}

o presente estudo tem por objetivo a aná1. ise da rentabilidade economica da produgăo de hortalías no DF, buscando determinar os fatores que contribuem para o nivel de renda dos produtores. Os objetivos especiricos sâo os seguintes:

a) analisar as caracteristicas dos produtores de hortalicas do of;

b) determinar os fatores que afetam, significativamente, o resultado económico da produgro de hortalizas no DF. 
2. METOROLOGTA

E. B. Base de dados

Em 1.986, o Centro Nacional de Fesquisa de Hortalicas (CNPH), da Empresa Arasileira de Fesquisa Agropecuaria (EMRAAFA), coletou un conjunto de dados sóciom econômicos junto aos produtores de hortalicas, localizados eir 1. nucleos rurais do mp (Mapa 1), mediante aplicacăo de questionarios. As informabes foram obtidas com o objetivo de atender às exigencias do projeto de Estudo do rmpacto Sóciomeconomico da Fesquisa de Hortalicas da EMBFafa.

A deterninacto da amostra pol feita com base nos dados do Cadastro de Frodutores da Empresa de Amsistencia Ténica e Extenstao Rural (EVATEF/nF), gendo que a disponibilidade de recursos para o acompantamento dos produtores no campo, limitou em 78 o numero de produtorse entrevistados (Tabela 6 ).

\section{2.e. Localizacoto das propriedades}

On estabelecimentos agricolas amostrados, sibualn-we, em méda, a $42 \mathrm{~km}$ do centro de comerejalianato (CEASA/DF). OS Estabelecimentos de menor área están localizados em regiobes mais proximas das zonas urbanas,

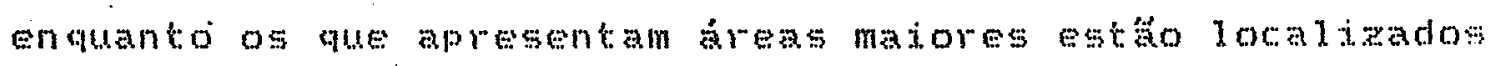
majs distantes da zona urbana. 
ce.

2.3. Informağess básicas

Nos questionários, estäo regtstradas informacóes sobre o "stakus" social e económico dos produtores, estrutura fundiára e uso da terra, utilizacăo de máquinas E equpamentos måowemobra capital imobilizado, utilizactio de insumos e tocnologias modernas, despesas gerajs, Hinanciamentose inyestimentos realizados, recebinentos de assistencia ténica, nivel de renda e qualidade de vida.

2.4. Avaliacăo da qualidade dos dados

A andise desenvolvida sobre os dados coletados. pelo Frojeto de Fesquisa do CNFlortaligas, da EMbFapa, foi realizada na preseuposido de que os mesmos nấo estavam sujeitos a emos de medida ou que os erros eram insignificantes para comprometer os resultados

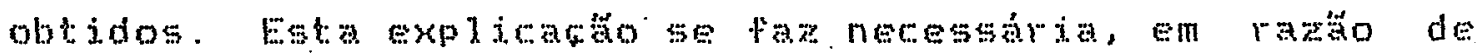
que 2 inatora dos produtores infomantes noto mantem registro de contabilidade agricola em suas propriedades. Entretanto, apesar da delieiencia apontada, os dados coletados gáo os mais pidedignos que se poderia conseguir. 
23.

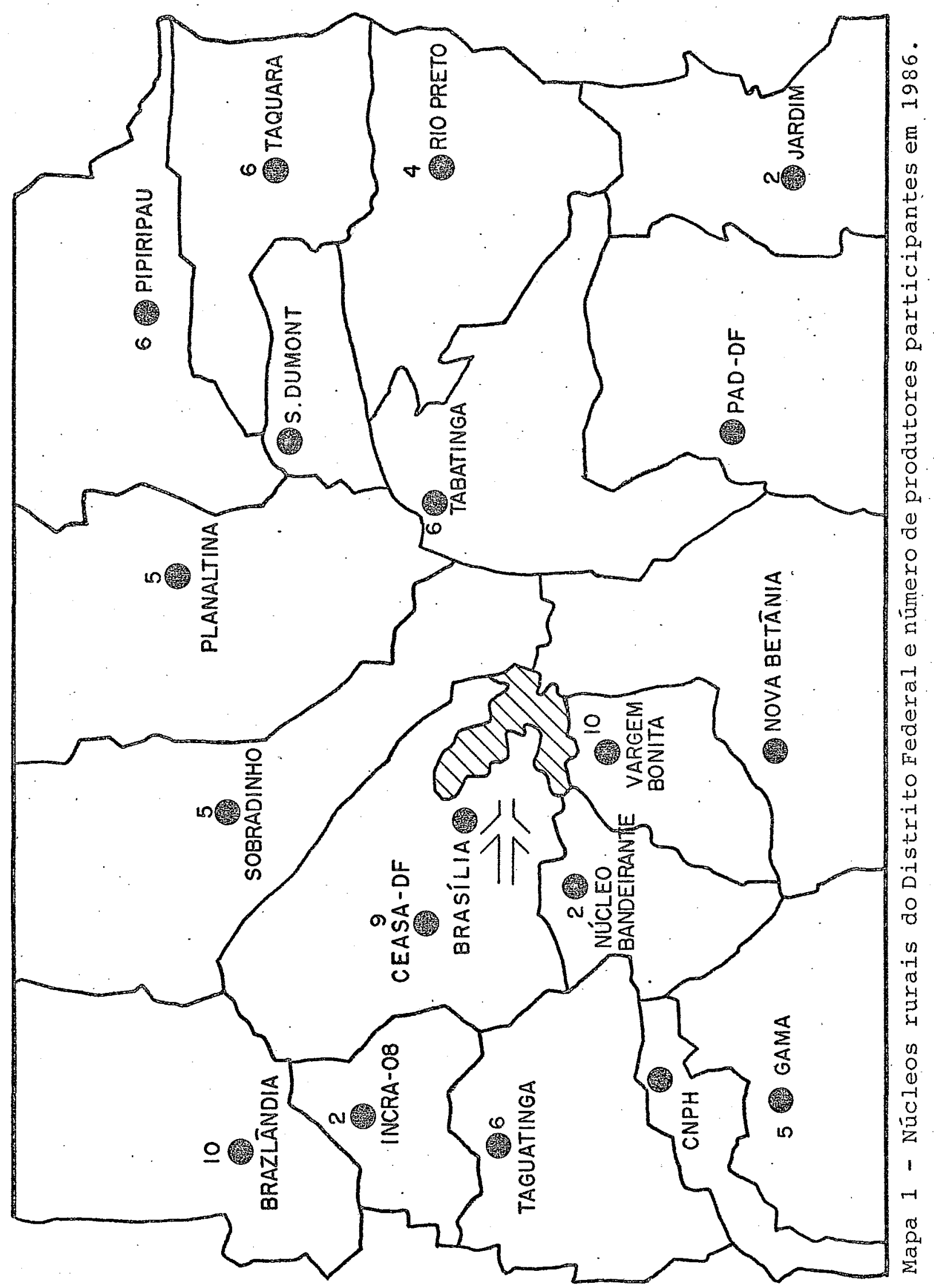


Tabela 6 - Numero de produtores de hortalifas entrevis.tados, segundo o nucleo rural do of em 1986.

Núc leo Fural no. de produtores

\begin{tabular}{|c|c|}
\hline Vargem Bonita & 30 \\
\hline Ceasa & 09 \\
\hline Taguatinga & 06 \\
\hline Brazlandia & 10 \\
\hline Inera & $\theta e$ \\
\hline Gama & 65 \\
\hline Jardin & $\phi 2$ \\
\hline Rio Preto & 04 \\
\hline raquara & 06 \\
\hline Tabaringa & 06 \\
\hline Fipiripau & 06 \\
\hline Flanaltina & 0,5 \\
\hline Sobradinho & 05 \\
\hline Nuc leo Barideirante & 00 \\
\hline
\end{tabular}

Fonte: Mados da pesquisa.

Este conjunto de dados serviu como base para o estudo da analise de rentabilidade da producto de hortalifas no DF, utilizandomse a metodologia descrita a seguir. 


\subsection{Metodologia de andise}

Para atender aos objetivos desta pesquisa, foi feita, injoialmente, uma andise descritiva das principais caracteristicas dos produtores de hortalicas do br. Em seguida, será feita uma anatse estatistica dos efejtos de algumas variaveis sobre os resultados economicos de producto de hortalicas.

\subsubsection{Fundamentos da ankilise de regressăo}

os fundamentos da analise de regressäo utilizados neste estudo foram baseados em KMENTA (3978), HOFFMANN \& UTETRA (1983) E JOHNSTON (1986).

Foram estimaros dois modelos alternativos: um na forma lineare outro utilizando os logaritmos (comun) dos valores das variáveis consideradas, com o objetivo de obter o melhor modelo de ajustamento da. regressato.

o modelo linear pode ser expresso, estatisticamente, como na equarăo (1):

$$
Y_{i}=b_{0}+b_{i} x_{j .1}+\ldots+b x_{j . p}+e_{j}
$$

- para o modelo logarítico, a equaka pode ser expressa como na forma (2) abaixo: 
26.

$\log Y=\log a+b \log _{i} X_{i 1}+\ldots+b \log _{i p}+109$

onde:

$$
\begin{aligned}
& r \quad \text { yariável dependente; } \\
& \text { be a intercopto da funciós } \\
& 0 \\
& \text { b. ...b } \\
& x, \ldots, x=\text { yariáveds independentes; } \\
& e_{i}=\operatorname{ercos} \text { aleatorios; }
\end{aligned}
$$

0 ajustamento dos modelo: aos dados amostrais foman efetuados pelo mécodo dos Quadrados Minimos Drdinátos.

A eficiencia das equacbes das regressobs foram avaliadas com base no coeficiente de determinatäo e múltiola (n) Y.

Fara testar o nivel de signticancia das regressés e das estimativas dos parametros obtidas pelo método dos Quadrados Minimos ordinários, foram utilizadas as estatisticas de "F" de snedecor, e" "t" de student, res" pertivamente.

Fara a selezáo da equatio de regressáo. serăo utilizados os seguintes critomos:

a) coemena dos sinais dos coeficjentes de regressấo com 
os principios sconônicos:

b) que o valor de "F" seja significativo ao nivel de até 1. $0 \%$ de significância

c) que ovalor docoeficiente de deteminacáo mútsipla e

(F) seja relativamente alto (proximo de í);

d) naso existir nenhuma relacio linear exata entre qual quer das variávej independentes.

2.5.2. Variaveis do modelo estatistico

As variaveis utilizadas para o ajustamento das diferentes equabes, estâno discriminados a seguir. As varídveis sớc expressan em valores correntes de 1986.

\section{Variáveis dependentes}

\section{Fienda Eruta (Y)}

1

Egta variád refereme à fienda Bruta obti... da pelo produtor, proveniente da venda da produsto chorta lisas, frutas, gráos) ourras receitas carrendanento do terras, aluguel de máquinas e equipamentos, fretes, pres.tacto de servicos etc.) durante o ano de 1986. E expressa em Cow1.000,00.

Fenda Lifuida $(Y$ )

Feferewe a renda percebida pelo produtor, 
deduzindome da keceita Bruta, os custos variádis e os custos fixos. Os custos varjávejs (co) saro os gastos que variam de acordo com o nivel de producto na propriedade, como: gastos com adubos, sementes e mudas, defensivos, mäome-obra, fretes, combustiveis etc. os custos fixos (CF) sấo os gastos que nốo variam com a quantidade produzida, como: juros sobre o investimento realizado, imposto Pjxo, custo de arrendamento, depreciacäo etc. (HOFFMANN et a.i.i. 1984 ).

$$
\text { RL. }=\mathrm{FE}-\mathrm{CV}-\mathrm{CF}
$$

onde:

$$
\begin{aligned}
& \text { RL = Benda Liquida } \\
& \text { RE = Fenda Bruta } \\
& \text { CV = Custos Variaveds } \\
& \text { CF }=\text { Custos Fixos }
\end{aligned}
$$

o valor dadepreciacto dos bens de capital. via de regra, é calculado pelo método de reavalicáo anual, que consiste em avaliar o bem anualmente, independentemente do seu custo inicial, baseando-se no valor de revenda. A diferenoa dos valores da aval iago de un ano a outro E o valor da depreciactio (HOFFHANN et aij, 3.984). Entretanto, pela falta de dados sobre a reavaliacio dos bens do ano anterior, estimou-se a depreciacta, deduzindo um percentual sobre o valor dos bens declarados pelos produtom res, de acordo com a vida dit dos bens, conforme sugerido 
29

por HOFFMANW et a i.i. (1984).

\section{Uariáveis. Independentes}

Area cultivada de hortaligas ( $(x)$

1.

Esta varjável referemse d area cultivada em hortaljas na propriedade, no ano de 1996. E expressa em ha.

Valor do investimento em mácuinas e equipamentos $(x)$

Escra variáved referemse no valor dos bén: em máquinas e equipamentos eximtentes na propritedade; tajs como: microtrator, trator, implementos agricolas, véculos, conjunto de irrigafín (bomba, motor, canos etc) outros. Hexpressa en Crsi.000,00.

\section{Valor do investimento em benfeitorias ( $X$ )}

Esta variavel refere se ao valor dos bens em benfeitorias existentes na propriedade, incluindo casa sede, casa de colono, depósto, galpóses de máquinas e equipamentos etc. Is expressa em cas 1.000,00.

\section{Gastos com defensivos ( $x$ )

Esta variál referemse aos valores gastos com defensivos (herbicidas, fungicidas, jnseticidas e outros) durante o ano de 1986. E expressa em lozḱ.000,00. 


\section{Oastos com adubos ( $x$ ) \\ 5}

Esta variácel referemse aos gastos com adu... bos quimicos (NFK) e orgânicos, calcários e outros tipos de fertilizantes, durante o ano de 1986. E expressa em Cassi. 000,00

\section{Gastos com mâno-de-obra $(x)$

Esta variavel referemse aos gastos com másosdemobra, permanente temporaria, utilizada durante o

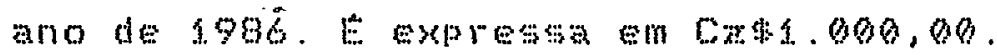

\section{Listância da propriedade (X)

Esta variand referewe a distancia da propriedade rural, em relacáo chasa/of, local onde 3 concentra grande parte da comerejalizacto dos produtos hortifrutigranjejros produzidos no af. E expressa pela distância medida en km.

\section{Educaço formal ( $x$ ? \\ 8}

Esta yorínel referewse ao grau do escola lidade formal (primério, secundáro superior) dos prom dutores analisados da seguinte forma:

analfabeto $=0$ ano de escola formal;

Primário = 8 anos de scola formal;

secundario 11 anos de escola formal; 
superior $=15$ anos de escola formal;

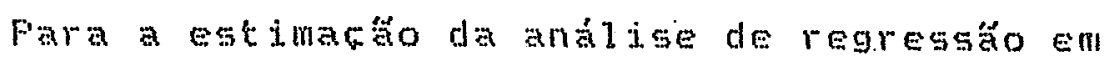
forma logaritmica, poi utilizado o valor $0,000 s$ para o grau de escolaridade $=0$ (analfabetor.

\section{Variavel "Dummy" ( $x$ )}

A variavel "dumme" ou binaria foj utilianda para separar os grupos de produtores de hortalifas (Apendices. f. e). Foi dado o valor o (aero) para o grupo de produtores que produzem exclusivamente hortalifas (Grupo 1.) e o valor 1 (um) para os demais produtores que diversiticam a producto com outras eultums (orupo e), no modelo linear.

Fara efeico de ansise na forma logaritmica, foi dado o valor i. (uim) para os produtores do Grupo 4 * ovalor 10 (dez) para os do Grupo e. 


\section{Resul. TANos e drscussao}

$$
\text { Neste capitulo, săo apresentados e discu- }
$$
bidos as principais caracteristicas sociais e econónicas dos produtores de hortalifas do IfF e, com base na análise de regressấ, os principais fatores que influenciam no rendimento económico de suas exploracóses.

\subsection{Resultados da análise descritiva}

Constata-se nesta pesquisa que a matoria dos produtores $(88,5 \%)$ reside nos estabelecimentos ruiris. os demais residem em propriedades situadas nos núcleos rurais $(6,4 \%)$ e na zona urbana $(5,1 \%)$. o tempo medio de residencia destes produtores na regito do nF é de cerca de 1.3 anos.

A idade dos produtores entrevistados varia de 25 a 70 anos, sendo que a idade média concontrada fod de 44 anos.

Qunto a educacto formal, o nivel dos prom dutores pode ser considerado alto. Cerca de $93,6 \%$ dos entrevistados sấ al labetizados, dos quais $53,9 \%$ possuem o 1o. grau, $33,3 \%$ o eo. grau, 6, $4 \%$ o nivel superjor somente $6,4 \%$ se declaram anal pabetos (Tabela 7 ). 
Tabela 7 - Nivel de escolaridade dos produtores de. hortalicas entrevistados em 1986. .

Wivel

escolar
No. de

produtores
$(\%)$

Anal tabeto $05.6,4$

fo. grau $42 \quad 53.9$

2o. srau $26 \quad 33,3$

Universitário 45 6,4

Total. 78 $1.00,0$

Fonte: Dados da pescuisa.

A taxa de anal fabetismo da populacăo brasi-leira da zona rural (pessoas com 15 anos ou mais) era, em 1.985, de 39,5\% (ANUARTO ESTATSSTTCO DO BEASTL, 1986). VErifica-se portanto, que, considerando o nivel educacional, os produtores do bF sto privilegiados em relacâ à média da populatăo rural brasileira. observa-se também, entre os produtores do of, uma alta concentratáo do nivel educaciom. nal nos ciclos de fo. Eo. graus. Resultados semelhantes também foram encontrados por LONGO (1985) e GokES et alij. os produtores e seus dependentes recebem assistência médica odontológica através de atendimento particular e da rede oficial, como por exemplo INFs, FUNFURAL E Fundacáo Hospitalar do dF cvinculada a Secreta- 
ria de Saude do Governo do nF.

\subsubsection{Estrutura econômita dos estabelecimentos}

\section{Uso da terra}

As atividades. dos producores săo. em geral. exercidas en seu próprio estabelecimento ( $73,1 \%$ ) somente 26.9\% nơ estöo anda devidamente regularizados quanco a propriedade das terras que vem utilizando.

As propriedades agricolas amostradas possuem, em media, 33,38 ha de área total cvariando de 2,5 a 238, ha) e e3, 41.ha de área media explorada, dos quas 7,11 ha sâ cultivados com hortaligas, num processo de plantios sucessivos ao longo do ano. Nos estabelecimentos de grandes áreas a mator parte das.terras é utilizada para a produca de grosos (soja, witho, fejojo etc.), fruticultura, criagâo de animais etc. sendo que uma reduzida pareela de terra futilizada na productóde hortalicas. A Practóno menor, dedicada à producto de hortalicas nessas propriedades, dáx sem Punsón das proprias caracteristicas dessa atividade, que são:

a) grande volume da producio por ha (tonelada/ha);

b) utiliagato intensiva de capital e mánowe-oba;

c) alto risco associado a productón.

Conforme o tamanho da propriedade es diferentes usos da terra, podem-se encontrar diferencas no 
resultado econónico e nos fatores que influenciam a renda dos produtores. Distingue-se, na anostra analisada, dois grupos de produtores:

a) produtores que produzem exclusivamente hortalicas, no total de $32(41,0 \%)$ estabelecimentos (Grupo 1);

b) produtores que além de produzirem hortalicas diversi-Picam a exploracăo com outras culturas, tais como: producto de grâs, frutas, eriacóses de animais etc., no total de $46(59,0 \%)$ estabelecimentos (Grupo 2 ).

3.1.2. Análise comparativa entre os dois grupos de produtores

3.1.2.1. Areas médias dos estabelecimentos

A área media dos estabelecimentos do Grupo f. fod calculada em ef, $99 \mathrm{ha}$, sendo 1.2, 09 ha de area explorada, dos quass 6,35 ha sáo destinados a producto de hortalifas (Tabela 8). Nos estabel feimentos do Grupo 2 , a área média má mor do que no orupo f, possuindo em média 41,31 ha de área total, sendo 34,29 ha de área explorada, dos quats 7,65 ha sốo destinados à producăo de hortalicas (Tabela 9$)$.

0 coeficiente de variacto (c.U.) demonstra que as areas medias das propriedades do orupo f é mais homogênea do que as do Grupo e, com excessăo da área total média. 
Nas áreas exploradas do crupo 1, verificam se. predominantemente, as atividades de producăo de horta 1.6as, reservando-se parte da area em descanso para futuros plantios (rotacto de area). No grupo e, as areas ex.-. ploradas săo utilizadas para a producto de hortalicas e, em sua maior parte, a producäo de frutas, grăos, criacós de andimats etc.

\section{1.e.e. Investimentos médios realizados}

Wos estabelecimentos do Grupo 1, os valores médios investidos por ba de area explorada foram de

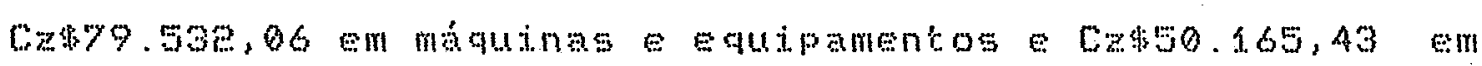
benfeitorias (Tabela 8 ). Nos estabelerimentos do brupo 2 , os investimentos foram da orden de całe6.689,50 em máquj.-ras e equipamentos e Cas44.790.65 monfentorias (Tabew 1a 9 , inferiores em relacta aos produtores do orupo 1 em $198,0 \%, 12,0 \%$, respectivamente.

o coeficiente de variaga do investimento médio en má quinas e equpanentos nas propriedades do orupo 1. apresenta major dispersa quando comparados as do Grupo e, demonstrando que o valor investido por ha de área media explorada e mas homogenea nessas propriedades do que em relaç̃o as do Grupo i. Entretanto, os investimentos medios realizados em benfeitorias nos estabelecimentos do Grupo 1 säo mais homogeneo do que os investimentos médios reali-zados nos estabelecimentos do Grupo 2. 


\subsection{3. despesas e receitas médias}

Para os produtores do brupo i. os gastos médios calculados por ha de area explorada durante o ano

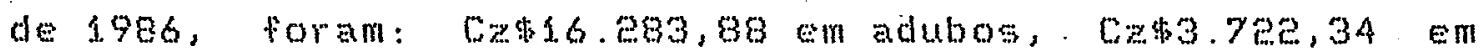
defensivos, Cos3.740,72 em mâdemobra e catso.694,59 em despesas diversas. Os produtores do orupo e toveram gastos medios de Co\$6.789,59 em adubos, Cas 160,39 com

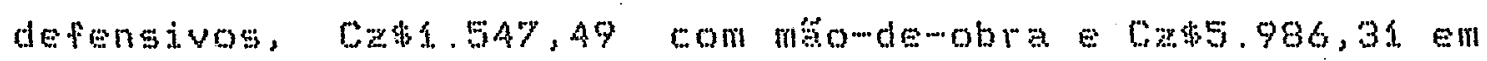
despesas diversas.

Como se pode observar, os produtores do Grupo a tiveram os gastos medios superiores aos do brupo e, indicando que o cultivo de horkalifas exige o uso in tonsivo de adubo e defensivo e, principalmente da mánde... obra.

o custo total medio por ha de área explo-

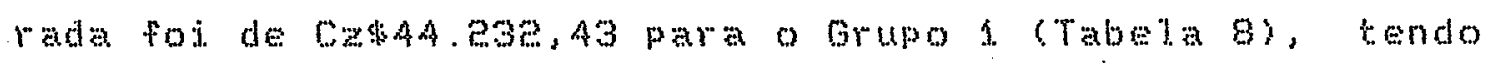

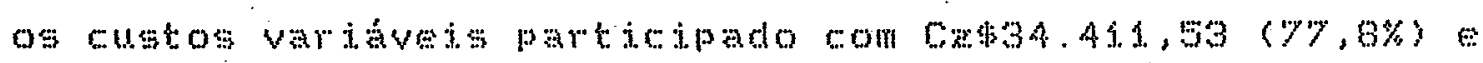

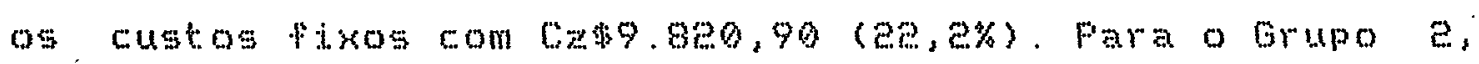

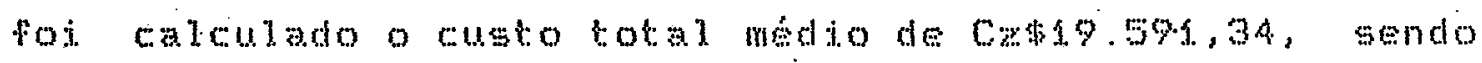

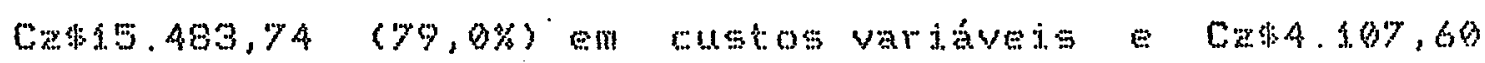
(elx) en custos tixos (Tabela 9 .

0 custo total médio e custo fixo nas prom priedades do Grupo 1 apresentam menores niveis de variafuro, demonstrando que os custos nesses estabelecimentos

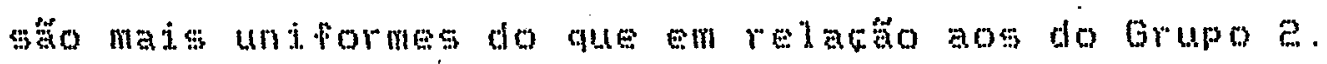


Quanto aos custos variávejs, o c.V. näo apresenta diterengas entre os grupos andisados.

Wos estabelecimentos do Grupo i, a Finda Bruta media por ha de área explorada foj de casp1.456,03, dos quais Cz\$90.633,71 $(99,4 \%)$ sân provenientes da produ-

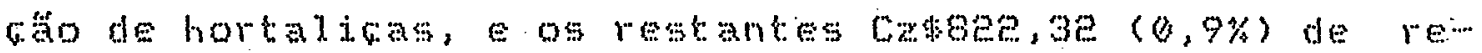
ceitas diveras (Tabela 8 ). Fara os estabelecimentos do Grupo e, a Renda Bruta modia por ha foi de Carsi.894.58, sendo Czw37.980,34 $(90,7 \%)$ sao provententes da producto de horalicas e as demaje de recejtas diversas, sendo

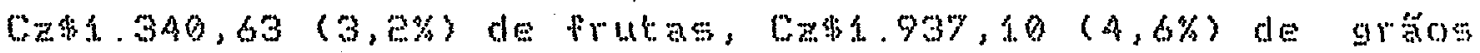

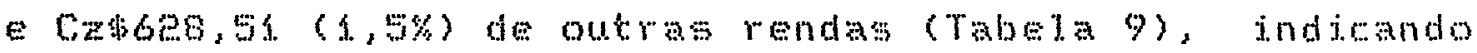
que os produtomes do orupo etem, tamben, como principal atividade a producto de how thatias.

Com relasto à Fenda Liquida, os producores

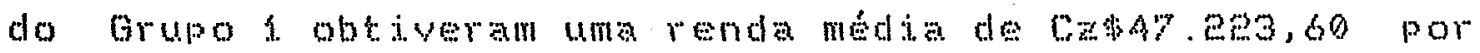
ha de area média explonda no ano, enquanto a renda dos

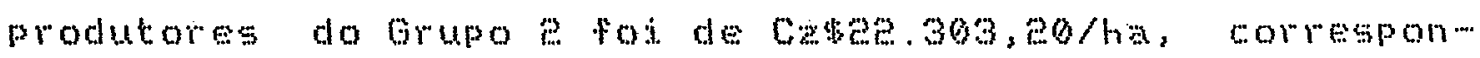
dente a $47, e \%$ da renda dos produtores do Grupo 1.

A Fenda Liquida dos sstabelecimentos do Grupo 1 apresenta menor coefieiente de variagáo, indicando que esses produtores tem um nivel de renda mais estavel do que em relacto nos do orupo e, com excessáo da variavel rendas diversas.

A diferenca no nivel de renda existente entre os grupos de produtores demonstra que o valor da 
producáto de hortalicas responde positivamente aos altos custos e de investimentos dispendidos na producato de hort. 1 is as

\subsubsection{Financiamentos bancários}

Com relacto aos financiamentos bancánios, os dados desta pesqujus permitiram constatar-se que $6 e, 6 \%$ do total dos produtomes entrevistados contrairam empresm timos no ano de 1986 . Dentre estes produtorew, $8,3 \%$ des. 4. inam os recursos.obtidos para custeio agncola, $38,5 \%$ em investimentos o os demas $(46,0 \%)$ aplicaram os recur em custeio e investimentos. Os yalores médios de finan ciamento para custeio e investimentos foram de

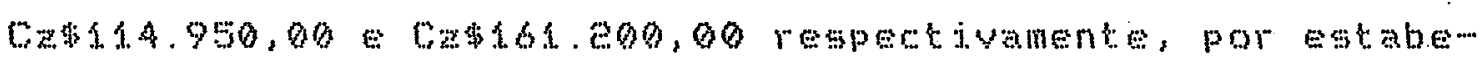
lecimento.

Esser resultado também se semel lonte ao obtido no estudo de $1.0 N 00$ (1985), onde $55 \%$ do total de 384 produtores entrevistados no pF, em fins de 1983 , tinta contrafdo emprestimo banedrio.

Deve se considerar, no entanto, que as taxas de juros nominats do mercado, no ano de 1986 (Flano cruzado), estavam bem abatxo as dos anos antoriores, o que pos "ivelmente contributu para estimular os produtores a contrair finarciamentos para custeios agricolas, investimentos de máquinas e equipamentos benfeitorias nas propried ades. 
Tabela 8 - Media, desviompatro e coeficiente de variacáo das principais variaveis economicas dos produ tomes de hortalicas do Grupo 2 do of em 1986.

(EIII:Cz\$1.000,00 de 1986$)$.

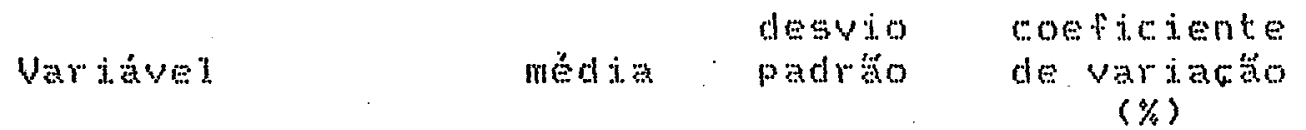

ITSTARCIA MA

PROPRIEIANE (km)

33,7

19,90

69,11

AFEA DE TEFFAS (HA)

- Area rota 1

e. 98

26.96

128,66

... Area explorada

12,09

5. 9.49

103,31

-. Area de hortalisas

6,35

4,12

64,88

(1)

INUESTTHENTO/HECTARE

Mánduse

matipamentos

$79,53 \quad-100,34$

128,68

- Benteitorias

$50,16 \quad 73,06$

3. $4 \mathrm{i}, 6 \%$

(1.) area media explorada.

Fonte: Pados da pesquisa. 
(Continuacta)

Tabela 8 - Média, desviomadráo e coeficiente de variagáo das principais variáceis econômicas dos produm tores de hortalicas do Grupo 1 do ne em 1986.

(En Cosi. 000,00 de 1986$)$

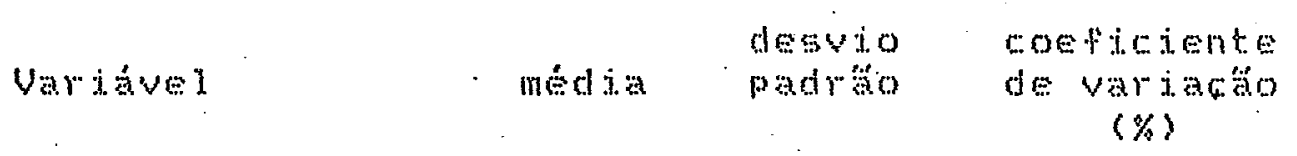

(1.)

CUSTOS/HECTARE

Custo total

44,23

$41+23$

93,28

-Custo variável

34,43

36,9

$1.07,30$

- Custo Pixo

9,8

i. 3,3 .

$1.5,1.7$

\section{(1)}

FEHUAS/HECTARE

Fenda de hortalicas

90.63

85,60

94,47

- Fenda diversas

0,8

2.76

336,58

-..Fenda bruta.

91. 40

85,75

$93,7 \%$

-..Fenda I íquida

47,28

56,66

$1.9,99$

(1) frea media explorada.

Fonte: lados da pesquisa. 
42.

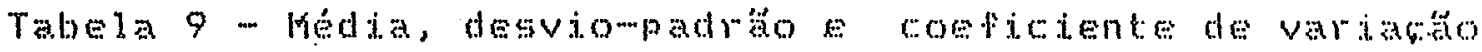
das princibas variáveis económicas dos produtores de hortalinas do Grupo 2 do for em 1986.

(Em Czos. 000,00 de 1986$)$.

\begin{tabular}{|c|c|c|c|}
\hline & $\cdot$ & desvio & coeficiente \\
\hline Var jável & méd & padráto. & de $\operatorname{var}_{(/ /)}$ \\
\hline
\end{tabular}

DISTANCIA IIA

FROFRIEIADE $(\mathrm{km})$

47.9

21. 73

45,37

AFEA IIE TEFFAS (HA)

-Area total

4., 31

46,67

112,97

-Area explorada

31,29

37,12

118,63

-Area de hortalicas

7,69

10,00

130,98

(1.)

TNUEST IHENTOS/HECTARE

-Máquinase
equipanentos
$26,69.25,50$
95,54
-..Benfeitorias
$44,80 \quad 142,93$
319,04

(1) área media cxplorada.

Fonte: pados da pesquisa. 
(cont inuasta)

Tabela o- Média, desviomadräo coeficiente de variagăo das principais variaveis económicas dos produtores de hortalicas do Grupo 2 do bF em 1986.

(Em Casí.000,00 de 1986).

\begin{tabular}{|c|c|c|c|}
\hline Variável. & media & $\begin{array}{l}\text { desvio } \\
\text { padrâto }\end{array}$ & $\begin{array}{c}\text { coeficiente } \\
\text { de variacia } \\
(\%)\end{array}$ \\
\hline
\end{tabular}

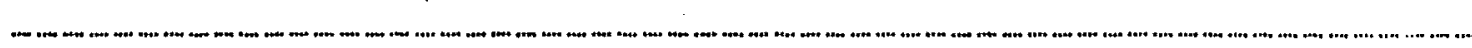

\section{(1)}

CUSTOS/HECTARE

- Custo total

$19.59 \quad 20,93 \quad 106,84$

-.custo variável.

45,40

16.46

106,33

- Custo tixo

$4,1.5$

5.61

136,50

\section{(1)}

RENLAS/HECTARE

Finenda de hortalifest

37.99

49,50

130,30

-. Fenda diversas

3.91

5,76

147,31

-..Fenda bruta

41,90

$50,2 e$

$1.19,86$

- Fenda liquida

2.2. 30

40,66

182,33

(1) brea media explorada.

Fonte: Dados da pesqujas. 
3.e. Resultados estatisticos.

Apesar das diferencas apontadas" entre os doss grupos de produtores, näo foram observadas diferencas estatisticas signiticativas entre os grupos quando compa rados atraves da analise de regressäo (ver Apendice 1 ). Consequentemente, na andise estatistica dos fatores que influenciam a rentabilidade dos estabelecimentos, os dojs grupos foram consjderados como um grupo homogeneo.

0: modelos selecionados form ajustados pew 10 metodo dos Quadrados Mindmos Ordinarios, sob duas formas alternativas. Os resultados săo discutidos a seguir.

\subsubsection{Modelos I ineares}

- Resultados do modelo de renda bruta (Y)

0 costeinte de dexerminato multipla

e (n) spresentou o yalor de 0,794 ; indicando que $79,4 \%$ das varacoses na Renda Bruta sto explicadas pelas variaveis jndependentes jncluidas no modelo. o valor do teste "F" (33,21) foi estatisticamente stgnificativo ao nivel de is, indicando haver uma ata relazáonere a variável dependente as variavejs independentes anal isadas no modelo.

No modelo de regressto linear da Fenda Bruta, observase que os valores obtidos para o teste "t" demonstran que os coeficientes de regressán das variácis 
45

área cultivada em hortalicas (b) gastos com defensivos ..

(b) săo estatisticamente significativos ao nivel de $1 \%$ de 4

probabilidade no modelo analisado, demonstrando forte influêned destes fatores sobre a lienda bruta dos produm $\operatorname{tores}(T a b e 1010)$

o coeficiente da variável área cultivada de hortalicas (b) apresentou valor postivo na relacáo exisw A.

tente sobre a fienda bruta, indicando que um aumento da area cultivada de hortalicas nas propriadades analisadas resultaria no aumento da Renda Bruta. To fato, conforme constatado na andise descritiva dos produtores (3.s.), a renda da producto de hortalicas constitui a base da renda dos produtores.

A varivel gastos com defensivos tamben apresentou coeficiente $\left.{ }_{4}\right)$ com sinal positivo, indicando que um aumento no uso de defensivos resultaria em gantos na Fenda Bruta do produtor. Ango utilizato; ou utilin zacko deficiente de defensivos, pode acarretar forte atarue de pragase doencas, e resultar em baixo nivel de rendimento ena qualidade do produto colhido, pelo alto risco biologico associados com assas culturas.

Ocorre que, mesmo antsis de constatar a jucjôncia de pragas e doencas, os produtores de horta. 
1.jes antecipam o uso de defensivos na lavouna como forma de prevenir-se contra perdas na producto e garonetr a

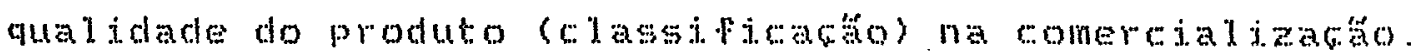

Mutos produtomes reconhesem que a aplicacóo de defensivos de forma corretiva caplicacto apos. a ocorrência de pragas ou doencas implica em diminuicáo dos custos de producáno. Forsm, a aplicaforo somente apos a incidencia das pragas ou doencas pode ocasionar perda parcial. ou total da producato, comprometendo, deste modo, o resultado econômico.

Estudos relacionados rom o concrole inte-.. grado de pragas doencas demonstran que a utiligata de defensivos na forma preventiva nato é correta do ponto de vista tecnico, implicando em matores gastos com defensivos 4. consequentemente, maior custo de producto.

Wo estudo de LOFES \& JABUONGKI (1987, em uma pesquisa sobre manejo de produgio de batata, os autores entatizan que os eteitos do uso indiseriminado dos agrotóxicos poden acarretar serjos riscos a saude humana ao meio ambiente, alér de aumentar consideravelmente o custo de producino.

Algumas proticas culturais podem ser utilizadas para racionalizar o llso de defensivos quimicos, como escolva da cultivar majs resistente as principais doencas, preparo do solo plantio de acoido com as reco- 
mendacofes tecndeas, e outras.

Os coeficientes das varidveis investimentos em máninas e equpamentos (b), gastos com máde-obra c.

(b) Edistancia da propriedade (b), mostraram-se signi-.. 6 7

ficativos aos niveis de $5 \%$ no modelo analisado.

A variavel $x$ coalor investido em máquinas e equipamentosi apresenta uma relasas positiva sobre a Fenda Bruta, indicando que um aumento na imobilizará de capital em mátuinas equipamentos destinados à prom. ducto, pode elevar a Renda Bruta Notans que os produ... tores utilizan intensivamente mácuinas e equipamentos em codo o ciclo da productio de hortalicas en operactes rela cionadas com preparabón da terra, trrigagáo, destocamento do produto para limpeza, lavagew automatica do produto

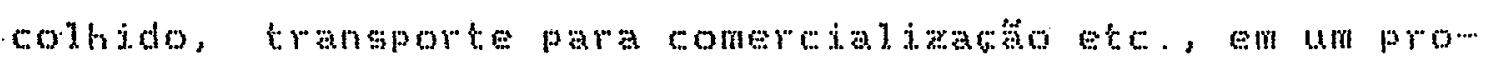
cesso de substituicto da mowdemobra - escassa dispen diosa - possibilitando, anda, o aumento da frea cultiva da, o que contribui para elevar a fenda Bruta do producor.

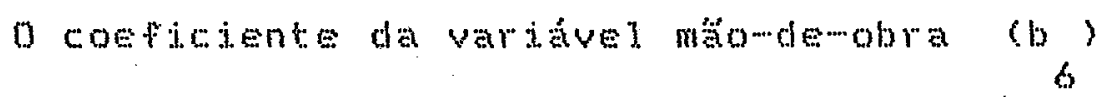

também está positivamente relacionada com a Renda Bruta, demonstrando que um aumento nos gastos desse fator, no processo de producta de hortalizas, pode aumentar o valor da Fenda Brutat.

Me fato, a utilizacta da mấo-de-obra se faz 
48.

presente de modo intensivo - em complementiago com o servico de máainas - no processo de producăo. .

As operacós relatonadas com controle de irrigacăo, tratos culturais, collheita manual, lavagem, classificacto e acondicioramento em embalagens etc. acar... retam gastos. maiores com máde-obra, relativamente aे produço de culturas agricolas mads tradicionais.

Gevido à alta perecibilidade da maioria dos produtos olericolas, uma diminuigáno no uso da mánomemobra en Pases criticas do processo de producso implica em serio prejuizo para orodusor, medida que ocorren atrasos nos tratos culcurais e na colneita.

0 coeficiente da variálel $x$ (distância da propriedade) apresenta sinal negativo em relacto a nenda Bruta, demonstrando que quanto menor a distancia da prow priedade em relagăo a CEASA/OH, mator a Fenda Bruta do produtor. Essa evidencia pode estar relacionada ao menor Eugto de transporte (pretes, menor tempo dispendido na comercial izaga e matos facilidades para o acompanhamento dos indicadores de presos praticados nos mercados de fatores dos produtos.

As demais variaveis, investimentos em benteitorias (b), gascos com adubos (b) e nivel de escolarjade (b) , nắo mostraram signjficancia estatistica 8 


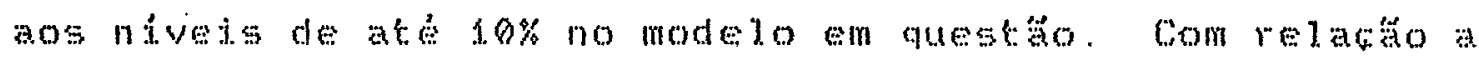
essas variaveis, é possivel dizer que no modelo linear utilizado na andise, náa existe evidencia suficiente de que possam explicar a fienda Bruta oblda pelo produtor.

A näomignificancia do coeficiente estimado da variavel investimentos em benteitorias (b) demonstra que näo existe uma relacto direta entre benteitorias e Fenda Brute do produtor de hortalicas. Verificawsentente os estabelecimentos amostrados, um investimento major nas wasas-sedes, onde se constata axistencia de moradias ...

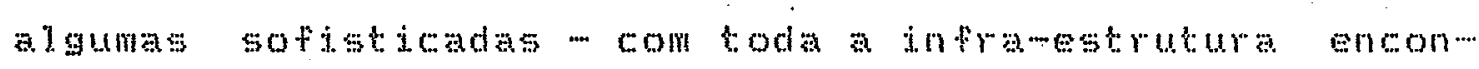
trada na zona urbana, como luz, astalto, telefone, onibus interligando as zonas urbanasece. cujos investimentos năo afetam diretamente a formacio da Renda Bruta do prow tutor.

outros investimentos am benfeitorias estác representados por gapöes e depositos para guada de insu... mos equpamentos para productio, como tamber depósios para armazenagem de produtos nato pereóveis.

Quanto a variavel gastos con adubos (x)

existe um consenso entre os produtores de horralicas do nF, na utilizacăo intensiva dos insumos agricolas, prin... cipalmente de adubos e defensivos, objetivando garantir o nto rendimento das hortalicas. A nổomignificancia do 
coficiente ostimado pode indicar que, possivelmente, os produtores deven estar wit izando niveis inadequados de fertilizantes, com criterios de escolba feitos em base a cotoria.

Embora o nivel de escolaridade dos producom res, em mutros estudos economicos, constitua um inportante fator explicativo do desempenho economico, o coeficiente da varjável nấo mostrou significancia até o nivel de $10 \%$ de probabilidade neste estudo. Fesultados semelhantes também foram obtjdos por LAFA (1975) Em um estudo uti.1... zando dados dos bovinocultores dos municipios de Encruzi.w Ihada Itapetinga (BA).

Segundo FFEIFE (1979), na pesquisa dos faw tores que explicam as diferencas de rendas entre pequenos produtores rurais do municipio de cruzedro do sul (ns), concluiu que o nivel de escolaridade náp aferou a fienda Línuda dos produtores de modo significativo.

No caso dos produtomes do DF, uma das posm siveis explicacoss pode deorrer do fato de que, tendo a maioria dos produtores alto nivel de escolaridade em relaxa a média da populacáo rural brasileira, o nivel da Fenda Eruta pode estar assocjado muito mais com a experioncia na utilizacto de puaticas modernas de produrso - adquirida atraves do servico da extensáto ou outros meios - do que com o nivel de escolarjade. 
- Resultados do modelo de renda liquida (Y)

0 coeficjente de deteminacto mútipla

a.

(F) encontrado para o modelo foj de 0,566 , ou seja, 56, $6 \%$ das variacós na Renda Liquida sto explicadas pelas varisueds independentes do modelo, interior no encontrado para o modelo de Fenda Rruta. Entresanto, o valor do teste "F" (11,e7) apresentou o nivel de significancia do $1 \%$ de probabilidade, mostrando que as variaveis selecionadas contribuen para a esplicara do modelo analisado (Tabela 1.9.

$$
\text { No modelo de Fenda Liquida (Y), os }
$$
coeficiontes das variaveis independentes, frea de horta licas (b), investimentos em benfeitorias (b), astos com detensivos $\left(b, 7\right.$, gastos com adubos $\left(b^{\circ}\right)$ e distaneta da propriedade $\left(b_{7}\right)$, se mostraran significativos ao nivel de 1\% de probabilidade; o que enfatiza a importancia desses fatores na analise da fenda linduida dos produtores de hortal inas do of

o coeficiente da variácel area de hortalisas (X) mostrou uma relato positiva com a fienda 1.

Liquida, indicando que um aumento da área cultivada pode 
resultar em um incremento na Fenda l. iquida dos produtores; de maneira semelhante ao resultado obtido no indelo de Fienda Bruta.

o coeficiente da variável investinentos ea benfeitorias (b) apresenta, neste modelo, um resultado significativo, ao contrário do que aconsece no modeda de Fenda Eruta. Todavia, a relato peranece negativa, ou seja, uma diminuicto no investimento com benfeitorias pode resultar en un aumento na Fenda líguida do produtor. Considerando que os investimentos em benteitorias nato tem una relacion direta con a renda dos produtores conforme andise descrita no modelo de Renda Bruta), o resultado estatistico indica que o investimento en benteitorias contribui negativamente na Fenda Liduda, atraves das despesas de manutencáno, depreciacto e outras, principalmente em investimentos de casasede possuve mente, as inversöes de capital em benteitorias săo reali. zadas para oferecer mator conforto e bem estar aos famili... ares, independentemente da repercussăo economica no nivel de renda familiar. E bom lembrar que grande parte dos prom dutores amostrados $(98,5 \%)$ reside nas propriedades produtoras.

As variageis gastos com defensivos $(x)$ e dietancia da propriedade $(X)$, mostram as mesmas relacós 
53.

encontradas no modelo de Renda bruta, observandowse, no entanto, o rivel de $1 \%$ de significancia da variável distância da propriedade no modelo de Fenda Liquida e de $5 \%$ de sgntficancia para o modelo de fenda Bruta.

o coeficiente estimado da variável gastos com adubos (b) apresenta uma relacto negativa com a Fenda Lifuda, ao nivel de $1 \%$ de significancia, indicando que uma reducăo no uso de adubo, pode resultar em um aumento na Fenda Liquida dos produtores. A reducto dos gastos com adubos, pode ser viabilizada atraves da pratica de antise perjodica do solo satota por reduzido número de produtores de hortalicas do nF), possibilitando ao produtor suprir somente os nutrientes necessirios para a planta, do forma racional economica, propiciando un aumento ne Fenda Lifuida do produtor.

As demais variáveis, investimentos em máquinas e equipamentos (b), gastos com môno-mebra (b) enivel de escolaridads (b)' consideradas no modelo, nấ mostraram significativos ate o nivel de $10 \%$ de probabilidade. Interemse tamberm, gue no modelo linear utiliagdo. na análise, näo existe evidencia suliciente de que estas va... rívejs posmam explicar a Fenda Líguda dos produtores $($ Tabela 10$)$ 
Tabela 10 - Valores estatisticos das regressöes lineares múleiplas dos dados da amostra dos produtomes de horladigas do IF Em 1986 .

\begin{tabular}{|c|c|c|}
\hline \multirow{2}{*}{$\begin{array}{l}\text { Uardaveds } \\
\text { independentes ( } x i \text { a) }\end{array}$} & \multicolumn{2}{|c|}{$\begin{array}{c}\text { Variácises dependentes } \\
\text { (Yis) }\end{array}$} \\
\hline & $\begin{array}{c}\text { Benda } \\
\text { Bruta }(Y)\end{array}$ & $\begin{array}{l}\text { Fienda } \\
\text { Liquida }(Y)\end{array}$ \\
\hline Jntercesto & 151,260 & 178,252 \\
\hline$(x)$ area de hortaldas & 34,047 & $29,546 *$ \\
\hline$(x)$ investimento em máqui- & $29 x+8$ & . \\
\hline$(x)$ investimento en benfej & & \\
\hline Dorias & $-0,0.32$ & $-0,103 \%$ \\
\hline$(x)$ gastos com defensivos & 7,0004 & $6,373 x$ \\
\hline$(x)$ gastos com adubos & $0,0.48$ & $-1,100 x$ \\
\hline $\begin{array}{l}(x) \text { gastos com mónomobra } \\
6 .\end{array}$ & $5,736 * 2$ & $.4,085$ \\
\hline$(x)$ distancia da propriedade & $-2,914 \%$ & $-3,275$ \\
\hline$(x)$ nivel de escolaridade & $-15,525$ & $-33,464$ \\
\hline $\begin{array}{l}\left.{ }^{2}\right) \\
\text { determinacto multipla }\end{array}$ & 0.794 & 0,566 \\
\hline Teste "F" de snedecor & $33,25 *$ & $11,27 \ldots$ \\
\hline 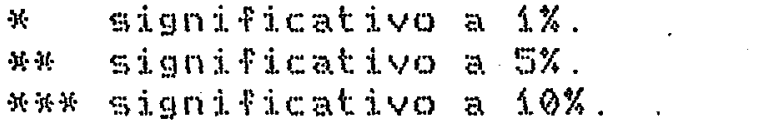 & & \\
\hline
\end{tabular}


3.2.2. Modelos logarismicos.

Das modelos logaritimicos năo apresentaram methor performance na explicaca da renda, quarido compa rados aos modelos lineares - como indicado pelas estatis ticas utilizadas - razo pela qual năo serăo comentadas neste trabalho (veja Apendice e). 
4. CONCLUSOI::S

Os resultados obtidos da andise descritiva dos produfores de hortalifas e das andises de regressóno sobre os dados coletados no nF em 1986, possibilitaram as seguintes conolusobes:

a) a matoria dos produtores amostrados $(88,5 \%)$ reside nos estabelecimentos rurais, o que, possivelmente, permiteThes administrar acompanar as atividades desenvol vidas na propriedade, de forma bastante próxima;

b) o nivel de escolaridade dos produtores amostrados \& atco, em comparata com o observado no brasil. Somente $6,4 \%$ dos entrevistados năo saber ler ou escrever, en quanto que no arasil, em $1905,39,5 \%$ da populacăo rural brasileira (pessoas com so anos ou mass) era anal labeta. observase uma alta concentracăo do nivel educacional dos producoresm do hif nos eiclos do 10. grau $(53,9 \%)$ e do eo. grau $(33,3 \%)$;

c) as propriedados do pequenas áreas estóno situadas mais próximas das aonas urbanas, e as que apresentam majores áreas estä́ localizadas em núcleos rurais mais distantes. Notame que a majomia dos estabelecimentos de pequenas árease, portanto, majs proximos dos centros urbanos, têm como fonte principal de renda a producato 
de hortalifas. A area total media calculada para as propriedades especializadas na producáo de hortal ias (Grupo 1) E de es, 98 ha, enquanto nos demas estabelen cimentos que, alem do cultivo de hortaligas, dedicam se a culturas anuads e criacós (orupo e) é de 41,31 ha. Ds primeiros dedicam, em média, 6,35 ha de area cultivada às hortalicas, enquanto os demajs estabelecin. mentos reservam, em méda, 7,65 ha para aquelas culturas;

d) en fungấo da propria caracteristicas na producăo de hortalicas, os produtores uilizam intensivamente os insumos modernosis (adubos e depensivos), mäomemobra, máquinas e equpamontos. A grande majoma dos produto:res adotam praticas agricolas modernas, tendo como objetivo garantir alta produtividade, qualidade do produto e assegurar a mákima rentabilidade económica possivel;

e) Denda Bruta dos produtores está diretamente relacionada com a frea cultivada de hortalisase com os gastos com defensivos. A Renda Bruta tamben é afotada pelos investimentos em maquinas equipamentos, e gastos com mónomobra.

Os resultados indican, também, que as propriedades localizadas mais proximas dos centros de comercializacto apresentam majores margens de Renda 
Bruta. Os investimentos realizados com benfeitorias, gastos com adubos e o nivel de escolaridade, aparentemente, năo estáo relacionados com os niveis de fenda Bruta (Tabela 10);

i) a Fenda Liquida média por ha de area explorada nos estabelecilientos dos produtores do Grupo 1 foi superior em lif, $7 \%$ em relacto no Grupo e, demonstrando que, apem sar dos alcos custos exigidos na producto de hortaliwas, Existe uma relaca positiva desta atividade com os resultados económicos;

9) a Fenda Lifuida dos produtores esta diretamente rela cionada con abea cultivada de hortalicas e com os sastos com defensivos. Os investimentos em benfeitorias, gastos com adubos e distancia da propriedade tambem se mostraram relacionados com a Renda Línuda, porem de modo negativo. Aparentemente, os investimentos em máquinas e equipamentos, gastos com môno-de-obra nivel de escolaridade nso esta diretamente relacio nados com a Renda Líquida dos produtores (Tabela hos.

\section{SUGESTOES}

Algumas implicacós podem ser derivadas a partir dos resultados e conclusóses oblidas neste estudo. No escudo procurou-se avaliar a importancia e o impacto de 
algumas variaveis que, "a priori", foram consideradas importantes na formatâ da renda dos produtores. Evidentemente, é possivel que o modelo utilizado possa conter erros de especificacäo no tocante as variávejs utilizadas. Além disso, é cambém posstivel que outros tipos de modelo, a 1 ados a uma diferente especificaśo de dados maior no: da amostra, por exemplos, conduzam a resultados diferentes. do que os que foram obtidos resse estudo. Nesse sentido. futura pesquisas devem ser encorajadas.

o impacto dos gastos com fertilizantes na renda foi inesperado (sigificativo, porém inverso). Este resultado indica que os produtomes de hortalicas possam estar usando este insumo de modo inadequado. Neste sentido existe, entre os técnicos que atuam na regiăo do bF, uma crenca generalizada com respeito ao uso incensivo de fercilizantes pelos produtores. Entso, futuros estudos com respeito a eficioncia no uso de fertilizantes pelos produtores devem ser recomendados. Este resultado pode tamben ser decorrente de atitudes de produtores com relasáo ao risco no uso de fertilizantes.

- Eapital investido em máquinas e equipamentos, gastos com mäo-de-obra o nivel de escolaridade nâo apresentaram, como se esperava, sinais significativos com relacáo ao nivel da Renda Eruta. Também estes resultados poden ser decorrentes de incorrectes na especificarăo destas variávis. De qual quer modo, nåo existem razooses 
suficientes para negar sua influência na formacóno da renda dos produtores de hortaligas do dF. 


\section{REFERENCIAS BIELTOGRAFTCAS}

ACOMFANHAMENTO MENSAL NO FRORUTO - CEASA/OF. (aIPaCE, batata, beterraba, cenoura, chuchu, pepino, pimentäo, re:polho, tomates. Brasilia, 1966.

ALUES, E.F.de.A. 0 dilema da politica agricola brasileira: produtividade ou expansăo da área agricultável. BYasia, EMBFAFA-MTD, 1983. 108\%.

AVUARTO ESTATISTTCO DO BEABTL - 1986, Fio de Janeiro. 47: 2.79-2ege, $\quad 1986$

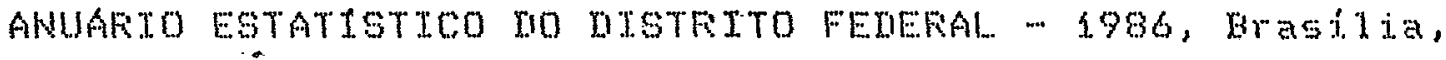
1.0: 472,1986

AUTLA, AF.D.; TFIAS, L.J.H.; FATUA, R.M. TMPactos socioeconomicos dos investimentos em pesquisa da EMBFAFA: resultados a congados, rentabilidade pespectivas.

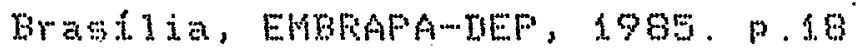

BFUNO, R.A.L. As condicós sociads da agricultura no Distrito Federal. Bratian, 1976. 99 p. (Mestrado Universidade de Brasilial.

CASTOF, 0.5. STLUA, J.8. da. Variaga estacional de prem Gos das hortaligas no mercado abadista do nif. Brasi.. Ija, EMBFAFA-CNFH, 1986. 16p. (Circular técnica, 1.). COMTSSRO DE FIANE JAMENTO AGRTCOLA MO MTSTFITO FEMEFAL,

Brasilia, If". Diagnóntico do Setor Agricola do Distrito Federal. Brasilia, 1983. 117p.

EMFFESA TIE ASSTSTENCTA TECNTCA E EXTENSAO RURAL, BNaSII Ia, 
IfF. Flano niretor $1989-1990$. Brasilia, 1989. 16p. FFETRE, L.M.de:M. Fatores que explicam diferencas de renda entre pequenos produtores rurais - Cruzeiro do Sul RS. Forto Alegre, 1979. 1140. (Mestrado-Universidade Federal do kio brande do sui).

HOFFMANK, Ri ENGLEF, J.J.dE C; SEFRANO, O; THAME, A.C. dE M; NEVES, E.M; Administracto da Empresa Agricola. 4. ed. Gấo Fauto, Piondira, 1.984. 3egp.

HOFFMANW, R. ¿ UTETFA, 5. Análise de Fegressăo: uma intro-

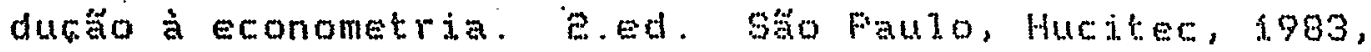
$379 p$

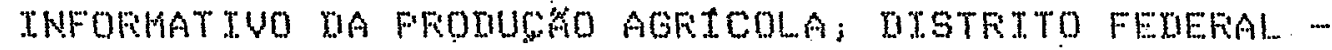
EMATER/DF, Brasilia, jan.- dez. 1986.

JoHNSTON, J. Métodos Econometricos. Såo Faulo, Atlas, $1986,317 \%$

KMENTA, J. Elementos de Econometria. Săo Faulo, At las, $1978,670 \%$

LAFA, J.A. Fatores que interferem na renda liquida dos bovinocultores de corte nos munjeipios de Encruzilhada e Itapetinga (BA). Vicosa, s97\%. B7p. Mestrado- Unjversidade Federal de Vicosal.

LoNoO, F.M.J. The role of information transfer in the adoption of agricultural innovations: the case of the Federal District of Brazil. Sheffield, 1985. 202p. (Moutorado - University of Sheffields. 
LOPES, C.A; JABUONGKJ, R.E; Circular Técnico do CNFHor talifas; Manejo da cultura da batata para o controle de doencas. Brasilia, CNFHortaligas, 1987, 6p.

OLIUETFA, C.A. da S.; MORETRA, H.M.; MAFOUELLI, W.A.; STLUA, W.L. de cee. Area irrigada, producäo e produtividade das principais hortalicas do Brasil - 1985/1986. Brasilia, 1988. (No prelo)

FASTORE, J. Mecisós em condicós de incerteza na agri... cultura. Revista de Economia Rural, Brasiliam If, $14(1), 14-63,1976$.

FEBAYlE, Ri. A Area Fural do Distrito Federal Erasileiro. Revista Erasileira de Gepgrafia. Fio de Janeiro, 33 : $39-83,1974$.

FICHTER, H.U. \& KONSEN, 0.6. Oferta agricola e fatores explicativos da renda em pequenos erandes estabelecimentos rurais. Revista de Economia Rural, Brasilia, $17(3): 15-24,1979$.

SCHULTZ, T.W: A transformaso da agricultura tradicional.

Rio de Janeiro, Zahar, 1965. eopp.

UENO, L.H. \& AMARO, A.A. Análise de variacáo estacional de precos, quantidade e mark-up de produtos horticolas. IN : CONGRESSO BRASTLETKO DE OLERTCULTURA, 2O., Brasilia, 1980. Resunos. Brasilia, EKRRAFA/EMBRATER/SOR, 1980. P. $198-199$. 
64

AFENATCE 
Apêndicen 1

Foi feito um teste para verificsr a existência de diferencas no nivel de renda entre os dois grupos de produtores. Fara tanto, utilizoumse a variável. "dumme" $(x$, nos modelos anal isados.

0 teste de significancia para a referida variavel mostra que näo existe diferenca de renda entre os grupos de produtores. Fortanto, neste estudo, adotou-se c critério de estudar os produtores de maneira agregada.

As equacöes estimadas para a realizacáo do teste encontram-se nat tabela a seguir. 
Valores estatisticos das regressöes lineares múltiplas dos grupos de produtores de hortalisas do DF, 1986.

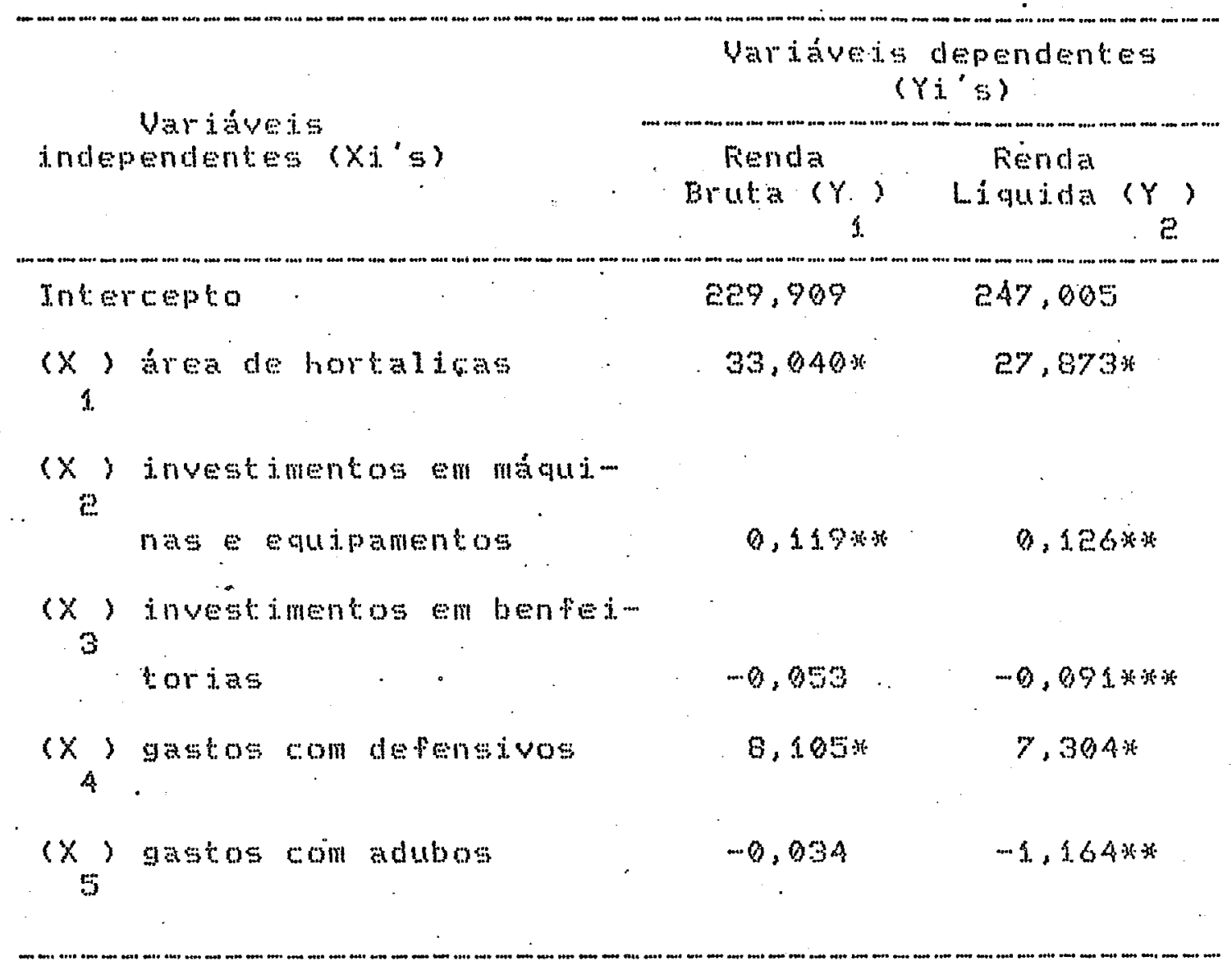

* signiticativo a $1 \%$.

* significativo a $5 \%$.

** significativo a $10 \%$. 
(Cont inuationo).

Valores estatisticos das regressós lineares multiplas dos grupos de producores de horealigas do rof, 196s.

\begin{tabular}{|c|c|c|}
\hline . & \multicolumn{2}{|c|}{ 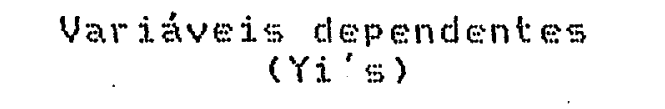 } \\
\hline $\begin{array}{l}\text { Variaveis } \\
\text { independentes (xi's) }\end{array}$ & $\begin{array}{c}\text { Fenda } \\
\text { Brute }(Y)\end{array}$ & 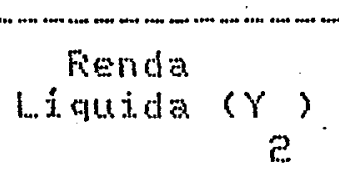 \\
\hline$(x, g)$ gastos com matom de obra & $6,420 \times 4$ & 4,330 \\
\hline$(x)$ distancia da propriedade & $-3,612.4$ & $-3,88 e * \pi$ \\
\hline$\left(x_{g}\right)$ niyel de escolaridade & $\cdots 1 \%, 059$ & $-30,874$ \\
\hline$(x)$ "dumbl para grupos & $-107,015$ & $-89,106$ \\
\hline $\begin{array}{l}\text { (E) coeficiente de } \\
\text { determinaráno multipla } \\
\text { Teste "F" de snedecor }\end{array}$ & $\begin{array}{l}0.800 \\
30,30 x\end{array}$ & $\begin{array}{l}0.63 \% \\
13,30 \%\end{array}$ \\
\hline 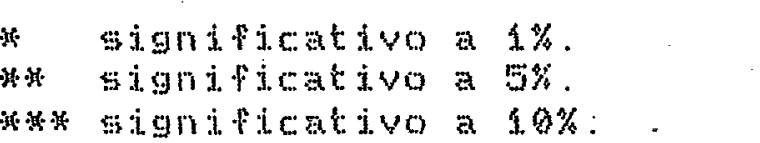 & . & \\
\hline
\end{tabular}


Apendice 2

Valores estatisticos das regressöes múltiplas em logaritmo dos grupos de produrores de hortalifas do nf em 1986.

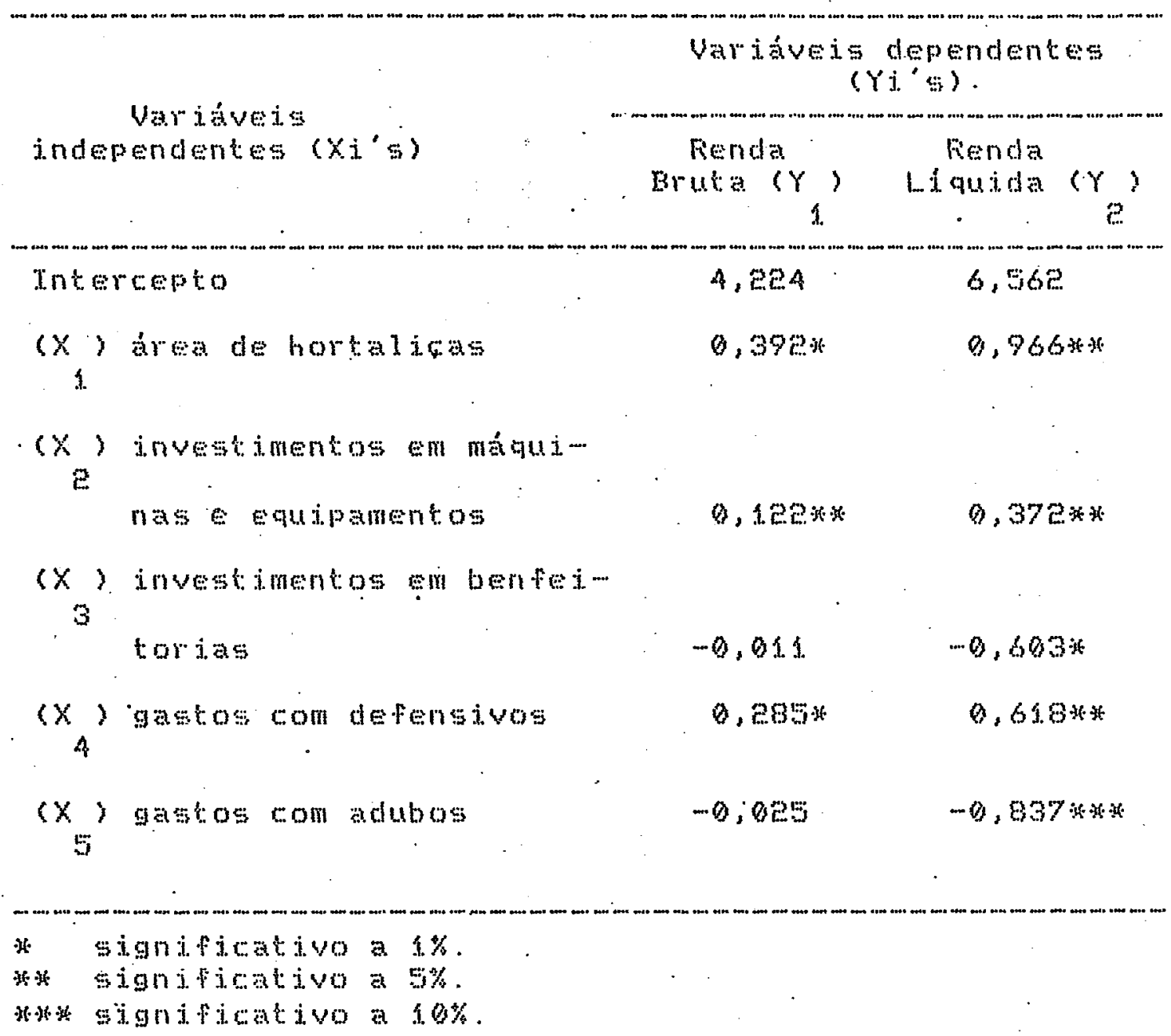




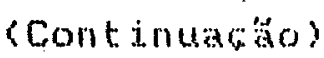

Valores estatisticos das regressốn multiolas em logaritmo dos grupos de produtores de hortalicas do lof en 1.986.

\begin{tabular}{|c|c|c|}
\hline & \multicolumn{2}{|c|}{$\begin{array}{c}\text { Uariaveje dependentes } \\
(Y i=s)\end{array}$} \\
\hline independentes $(x j \cdot s)$ & $\begin{array}{c}\text { Renda } \\
\text { Butat (Y) }\end{array}$ & $\begin{array}{l}\text { Fenda } \\
\text { Liquida ( } \gamma \text { ? }\end{array}$ \\
\hline$(x,)_{6}$ gastos com mäomdewobra & $0,176 x$ & 0,269 \\
\hline$\left(x_{7}\right)$ distância da propriedade & $-0, \operatorname{ceg}$ & $-0,661 * * 2 *$ \\
\hline$(x)$ ) nivel de escolaridade & 0,170 & 0,725 \\
\hline$(x,)^{\prime}$ "dummy" para grupos & $\cdots, 175$ & $-1,326$ \\
\hline 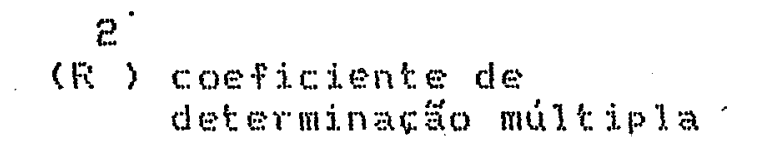 & 0,674 & 0,287 \\
\hline Teste "F" de snedecor & $17,79 \%$ & $4,48 *$ \\
\hline
\end{tabular}

* signiticativo a $1 \%$.

* significativo a $5 \%$.

* s. 